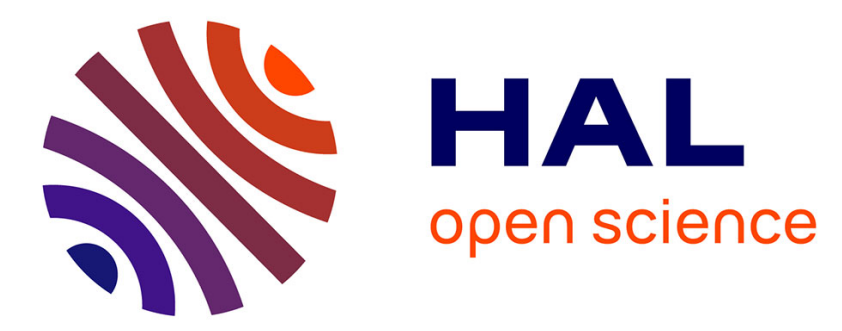

\title{
Occurrence probability of moderate to large earthquakes in Italy based on new geophysical methods
} Dario Slejko, Alessandro Caporali, Mark Stirling, Salvatore Barba

\section{To cite this version:}

Dario Slejko, Alessandro Caporali, Mark Stirling, Salvatore Barba. Occurrence probability of moderate to large earthquakes in Italy based on new geophysical methods. Journal of Seismology, 2009, 14 (1), pp.27-51. 10.1007/s10950-009-9175-x . hal-00535500

\section{HAL Id: hal-00535500 https://hal.science/hal-00535500}

Submitted on 11 Nov 2010

HAL is a multi-disciplinary open access archive for the deposit and dissemination of scientific research documents, whether they are published or not. The documents may come from teaching and research institutions in France or abroad, or from public or private research centers.
L'archive ouverte pluridisciplinaire HAL, est destinée au dépôt et à la diffusion de documents scientifiques de niveau recherche, publiés ou non, émanant des établissements d'enseignement et de recherche français ou étrangers, des laboratoires publics ou privés. 


\title{
Occurrence probability of moderate to large earthquakes in Italy based on new geophysical methods
}

\author{
Dario Slejko • Alessandro Caporali • \\ Mark Stirling • Salvatore Barba
}

Received: 19 March 2008 / Accepted: 16 July 2009 / Published online: 25 August 2009

(C) Springer Science + Business Media B.V. 2009

\begin{abstract}
We develop new approaches to calculating 30-year probabilities for occurrence of moderate-to-large earthquakes in Italy. Geodetic techniques and finite-element modelling, aimed to reproduce a large amount of neotectonic data using thin-shell finite element, are used to separately calculate the expected seismicity rates inside seismogenic areas (polygons containing mapped faults and/or suspected or modelled faults). Thirty-year earthquake probabilities obtained from the two approaches show similarities in most of Italy: the largest probabilities are found in the southern Apennines, where they reach values between $10 \%$ and $20 \%$ for earthquakes of $M_{\mathrm{W}} \geq 6.0$, and lower than $10 \%$ for events with an $M_{\mathrm{W}} \geq 6.5$.
\end{abstract}

D. Slejko $(\bowtie)$

Istituto Nazionale di Oceanografia

e di Geofisica Sperimentale, Sgonico (Trieste), Italy

e-mail: dslejko@ogs.trieste.it

A. Caporali

University of Padua, Padua, Italy

e-mail: alessandro.caporali@unipd.it

M. Stirling

GNS Science, Lower Hutt, New Zealand

e-mail: M.Stirling@gns.cri.nz

S. Barba

Istituto Nazionale di Geofisica e Vulcanologia,

Rome, Italy

e-mail: barba@ingr.it
Keywords Seismic hazard - Strong earthquakes • Probability • Italy

\section{Introduction}

Plate tectonics processes produce deformation within the crust of the Earth, and the measurement of such surface deformation is an important boundary condition constraint on the interaction of crustal blocks through time. The distribution in space and time of geodetically derived strain rate will correlate, to some degree, with the geometry and activity of the underlying seismogenic sources, as well as with aseismic processes. In this context, many studies around the world have used geodetic strain rates to estimate earthquake recurrence and probability, providing a valuable supplement or alternative to parameters derived from geologic and seismic catalogue data.

During the period spring 2005 to summer 2007 the Department of the Italian Civil Protection funded several seismological and volcanological projects. One of the seismological projects was entitled "Assessing the seismogenic potential and the probability of strong earthquakes in Italy" (designated S2) and its main goals were: (1) to identify of the seismic sources capable of generating destructive earthquakes (i.e. events with a magnitude larger than 5.5) and (2) to assess the occurrence probability of these events for the 
sources. The S2 project was organized in four tasks, and Task 4 was dedicated to the actual computation of the occurrence probabilities. One of the goals was to assess the occurrence probability of strong earthquakes using seismological information, and to calibrate the results with geodetic data. Our working hypothesis is that large earthquakes occur along major faults according to the characteristic earthquake model (Schwartz and Coppersmith 1984). According to this hypothesis, faults show a tendency to generate earthquakes of similar characteristics (magnitude, slip, rupture length, etc.). While considered overly simplistic by the Italian research community, the characteristic earthquake model is useful as a basis for the broad data-based and methodological comparisons made in this study.

Our efforts are strongly motivated by the need to find ways to augment the incomplete coverage of fault mapping in Italy to date. While the fault data set is considered to be $95 \%$ complete in the southern Apennines, it is at best only $70 \%$ complete in the rest of the country, and 50\% complete or less in the offshore (Valensise, personal communication).

Considerable international literature is available regarding the evaluation of the occurrence probability of strong earthquakes on well-defined faults (e.g. WGCEP 2003) and the assessment of time-independent (e.g.: Frankel et al. 2000) and time-dependent seismic hazard [California: 2007 WGCEP (2008), Italy: Peruzza (2006)]. However, two main problems thwart these efforts in Italy: (1) the knowledge of the seismogenic faults in Italy is incomplete in terms of the number of faults and their geometric and seismic characteristics and (2) constraints from geodetic data are problematic because the number of permanent global positioning satellite (GPS) stations in Italy is small, the fact that they have only been in operation a short time interval (about 5 years), and the campaign measurements provide velocities with a large associated uncertainty. Not surprisingly, areal seismogenic sources were defined for areas suspected to contain fault sources as yet unmapped in the Database of the Italian Seismogenic Sources [see Basili et al. (2008) for details]. In the S2 project, these seismogenic areas were used to estimate earthquake recurrence parameters from geodetically measured strain rates. Specifically, the geodetic strain rate would be converted into seismic moment rate $\left(M_{0} R\right)$ and then used to give an upper limit to the seismic potential of the seismogenic sources. Critical to this approach would be the assessment of $M_{0} R$ from GPS data, the association of this $M_{0} R$ to a geographical area, and the exact definition of a seismogenic source within the geographical area.

Our paper summarizes work undertaken thus far in the framework of the S2 project for the assessment of the occurrence probability in 30 years of moderate-to-large earthquakes within seismogenic areas defined in the Database of the Italian Seismogenic Sources. We develop estimates of $M_{0} R$ from: (1) observations from permanent GPS stations (geodetic constraint) and (2) from a 3D geophysical model that incorporates stateof-the-art knowledge on faults, and rheology, and is calibrated from GPS observations [geophysical constraint: Barba (2007)].

\section{Basic ideas}

Two types of seismogenic sources are defined in the Database of the Italian Seismogenic Sources (Fig. 1). These are mapped faults and seismogenic areas. The mapped faults are generally well constrained from geological and geophysical data, in that a complete geometric and seismic parameterization (length, dip, slip rate, slip-per-event, etc.) are available, along with an evaluation of the uncertainties associated with the source parameters.

Seismogenic areas do not contain mapped faults, but are assumed to produce earthquakes of magnitude 5.5 or greater based on other geological, geomorphological, and geophysical data. Features such as linear valleys along strike from the mapped faults are assumed to be fault controlled, but the lack of field mapping prevents the definition of fault sources at the present time. For the seismogenic areas, the polygon defining the overall source is given in the Database of the Italian Seismogenic Sources, along with the associated parameters (depth, strike, dip, rake, 
Fig. 1 Seismogenic areas (red) and mapped faults (yellow) in the Database of the Italian Seismogenic Sources [modified from Basili et al. (2008)]

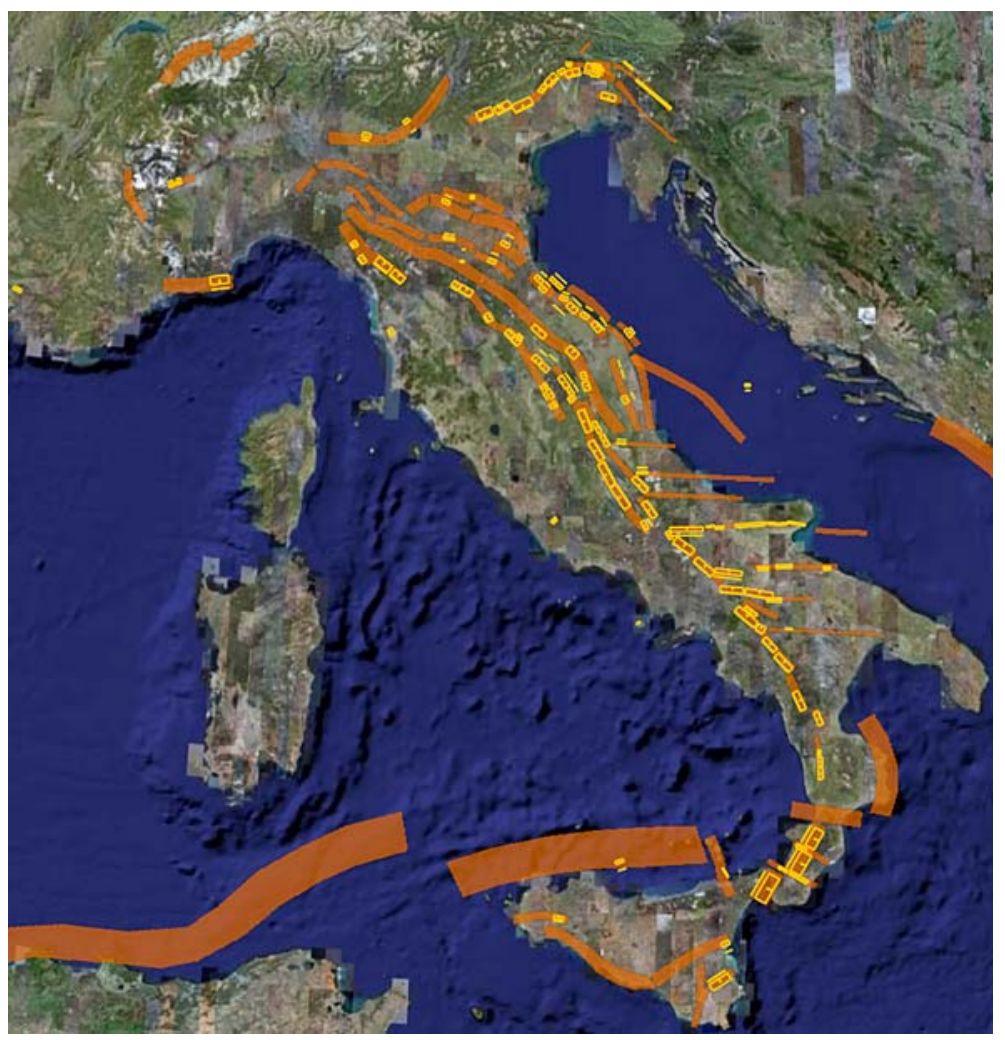

and slip rate, expected maximum magnitude) and uncertainty bounds.

The research documented here is aimed at defining the seismic potential of the seismogenic areas from the present strain rate in Italy and in consideration of regional seismicity patterns. As not all the existing faults in the seismogenic areas are known, a statistical procedure was designed (Stirling et al. 2007) to fill the empty space of the seismogenic areas with modelled faults of rupture lengths similar to those of the known fault sources.

The working hypotheses of the present study are as follows:

1. the regional geodetic strain is proportional to the seismic potential of the region (i.e. strain is released by earthquakes and aseismic creep);

2. the earthquakes occur on a pre-defined set of faults (a combination of mapped faults and modelled faults: the total number of faults in each seismogenic area is given by the sum of the mapped and modelled faults);
3. faults produce earthquakes according to the characteristic earthquake model (i.e. a tendency to produce a narrow range of earthquakes at or near the maximum size possible from physical constraints such as fault length) and the total regional $M_{0} R$ is released as the sum of characteristic earthquakes;

4. the general magnitude-frequency distribution of a region is described by the GutenbergRichter behavior, i.e. at the regional scale, the frequencies of the characteristic earthquakes form a Gutenberg-Richter distribution whose $b$ value is in agreement with the regional $b$ value, obtained by the past seismicity.

According to the above hypotheses, we assume that in the long-term $\left(10^{4}-10^{6}\right.$ years $)$ the majority of regional seismic release (proportional to the regional geodetic strain) will occur on the mapped or modelled faults, each acting according to the characteristic earthquake model and all together representing a Gutenberg-Richter behavior. 


\section{The data}

The network of some 160 permanent GPS stations has been in operation for a decade (19952005) and as part of the European Permanent Network of EUREF and the CERGOP 2 Project of the European Union. Additional local densification stations provide a valuable contribution to the estimate of the average surface strain rate. The strain rate budget for central Europe, determined from GPS observations, is of the order of 20-40 nanostrain per year in a circular area of 150-200-km radius of the eastern Alps (see Fig. 2 where a $100-\mathrm{km}$ ray is shown), corresponding to a velocity range of a few millimeters/year over distances of some hundreds of kilometers (Caporali et al. 2008).

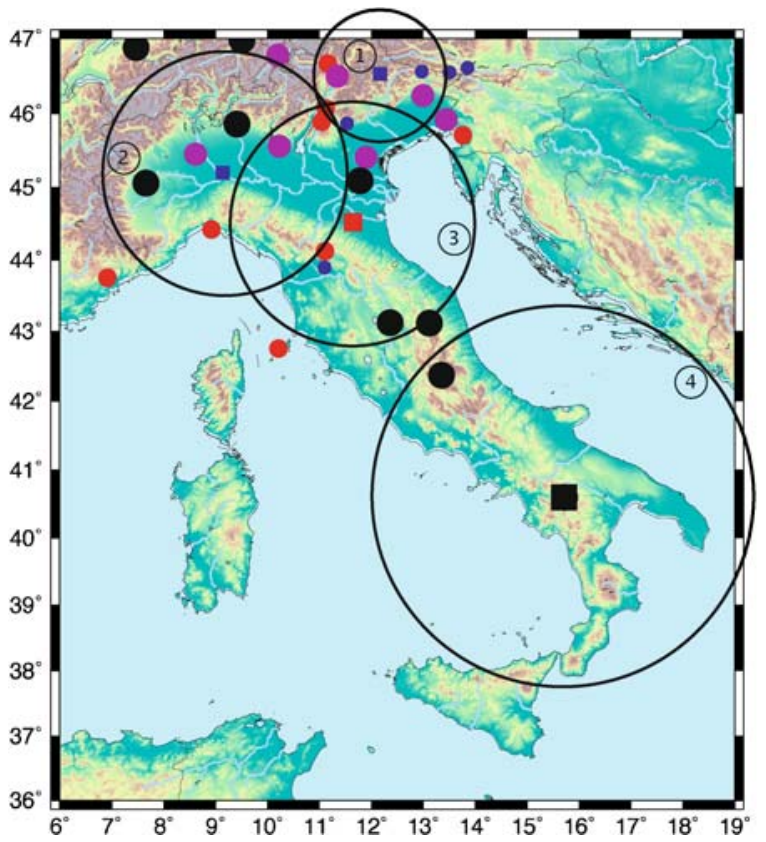

Fig. $2 M_{0} R$ (in N.m/year) computed from GPS observations. Blue small dots for $M_{0} R<1.0 \times 10^{18}$; red medium dots $1.0 \times 10^{18} \leq M_{0} R<2.0 \times 10^{18}$; purple medium circles $2.0 \times 10^{18} \leq M_{0} R<3.0 \times 10^{18}$; black large circles $M_{0} R \geq$ $3.0 \times 10^{18}$. The central GPS station of each domain is marked by a square with size and color according to its $M_{0} R$. The numbered large circles identify the four domains: 1 eastern Alps, 2 western Alps, 3 central Apennines, 4 southern Apennines
We compute velocity gradients by least squares co-location, which is a minimum variance algorithm capable of rigorously taking into account the stochastic properties of the input velocities (Caporali et al. 2003). For this purpose a covariance function is needed in order to represent the fall off of the correlation coefficient with the lag distance (average distance between the stations). Once the covariance function has been assigned then the velocity and the associated uncertainties can be computed at any point. For deformation analyses it is crucial to know how velocity changes spatially. The horizontal velocity gradient can be split into a symmetric and an anti-symmetric part. The symmetric part represents strain rate, whereas the anti-symmetric part represents a rigid rotation and is, hence, ignorable for deformation studies as the rigid rotation has no associated deformation. The symmetric part can eventually be diagonalized, yielding eigenvectors or principal directions of strain rate. The uncertainty in the components of the strain rate tensor can be quantified from the formal uncertainties of velocities at the actual stations. A final question relates to the method used to compute the strain rates. There exist two schools of thought. One school computes the strain rate on a regular grid, and propagates the uncertainty to account for the loss of accuracy as one moves away from the data points. The other school is more conservative, in the sense that the strain rates are computed only at those points where the estimates are sufficiently well constrained (i.e. where a significant number of stations are close to the site of interest). Hence the strain rate map is patchy, but well constrained where the calculations are made. We adopt this latter approach in our analysis. Specifically, we compute the strain rates at the location of those stations which are surrounded by four or more stations with known velocity within a search radius comparable to the decorrelation distance, that is, the distance at which the average correlation of horizontal velocity pairs drops of $50 \%$.

The horizontal velocities at the GPS stations (see Table 1) are inverted into maximum geodetic strain rate using a search radius variable from 100 to $300 \mathrm{~km}$, according to the number of stations 
Table 1 Strain rate $\left(\varepsilon^{\prime}\right)$ and moment rate $\left(M_{0} R 1\right)$, both with related standard deviations, calculated for the GPS stations

\begin{tabular}{|c|c|c|c|c|c|c|c|}
\hline STA & Lon. E & Lat. N & $\begin{array}{l}\text { Radius } \\
(\mathrm{km})\end{array}$ & $\begin{array}{l}\varepsilon^{\prime} \\
\text { (ns/year) }\end{array}$ & $\begin{array}{l}\sigma \varepsilon^{\prime} \\
\text { (ns/year) }\end{array}$ & $\begin{array}{l}M_{0} R 1 \\
\left(\mathrm{~N} \cdot \mathrm{m} / \text { year } \cdot 10^{18}\right)\end{array}$ & $\begin{array}{l}\sigma M_{0} R 1 \\
\left(\mathrm{~N} \cdot \mathrm{m} / \text { year } \cdot 10^{18}\right)\end{array}$ \\
\hline ACOM & 13.51 & 46.55 & 100 & 1.73 & 7.50 & 0.033 & 0.141 \\
\hline AFAL & 12.17 & 46.53 & 100 & 29.99 & 6.39 & 0.565 & 0.120 \\
\hline AQUI & 13.35 & 42.37 & 300 & 31.25 & 0.25 & 5.299 & 0.042 \\
\hline ARDE & 10.20 & 46.78 & 200 & 32.88 & 9.10 & 2.478 & 0.686 \\
\hline ASIA & 11.53 & 45.87 & 200 & 6.88 & 1.64 & 0.518 & 0.124 \\
\hline BRAS & 11.11 & 44.12 & 200 & 17.05 & 0.33 & 1.285 & 0.025 \\
\hline BRIX & 10.23 & 45.56 & 200 & 35.90 & 2.16 & 2.705 & 0.163 \\
\hline BZRG & 11.34 & 46.50 & 100 & 112.73 & 4.32 & 2.124 & 0.081 \\
\hline CAME & 13.12 & 43.11 & 300 & 36.68 & 3.06 & 6.219 & 0.519 \\
\hline ELBA & 10.21 & 42.75 & 300 & 8.97 & 2.00 & 1.521 & 0.339 \\
\hline GENO & 8.92 & 44.42 & 200 & 22.57 & 0.18 & 1.701 & 0.014 \\
\hline GRAS & 6.92 & 43.75 & 300 & 8.28 & 0.07 & 1.404 & 0.012 \\
\hline LEC1 & 9.41 & 45.86 & 200 & 49.63 & 6.22 & 3.740 & 0.469 \\
\hline MDEA & 13.44 & 45.92 & 200 & 29.31 & 0.87 & 2.209 & 0.066 \\
\hline MEDI & 11.65 & 44.52 & 200 & 26.30 & 0.84 & 1.982 & 0.063 \\
\hline MERA & 11.16 & 46.67 & 100 & 66.98 & 1.05 & 1.262 & 0.020 \\
\hline MPRA & 12.99 & 46.24 & 200 & 27.65 & 3.27 & 2.084 & 0.246 \\
\hline NOVA & 8.61 & 45.45 & 200 & 37.21 & 3.34 & 2.804 & 0.252 \\
\hline PADO & 11.90 & 45.41 & 200 & 31.58 & 4.56 & 2.380 & 0.344 \\
\hline PAVI & 9.14 & 45.20 & 200 & 8.24 & 3.28 & 0.621 & 0.247 \\
\hline PRAT & 11.10 & 43.89 & 200 & 10.69 & 1.13 & 0.806 & 0.085 \\
\hline ROVE & 11.04 & 45.89 & 200 & 18.09 & 0.46 & 1.363 & 0.035 \\
\hline ROVI & 11.78 & 45.09 & 200 & 44.33 & 7.14 & 3.341 & 0.538 \\
\hline SARG & 9.51 & 46.98 & 200 & 101.92 & 2.79 & 7.681 & 0.210 \\
\hline TITO & 15.72 & 40.60 & 300 & 45.24 & 1.91 & 7.671 & 0.324 \\
\hline TORI & 7.66 & 45.06 & 300 & 34.56 & 2.14 & 5.860 & 0.363 \\
\hline TREN & 11.12 & 46.07 & 200 & 18.69 & 0.13 & 1.408 & 0.010 \\
\hline TRIE & 13.76 & 45.71 & 200 & 17.44 & 2.95 & 1.314 & 0.222 \\
\hline UNPG & 12.36 & 43.12 & 300 & 31.95 & 0.51 & 5.417 & 0.086 \\
\hline VLCH & 13.85 & 46.61 & 100 & 8.12 & 9.18 & 0.153 & 0.173 \\
\hline ZIMM & 7.47 & 46.88 & 300 & 33.26 & 6.63 & 5.640 & 1.124 \\
\hline ZOUF & 12.97 & 46.56 & 200 & 3.38 & 1.60 & 0.255 & 0.121 \\
\hline
\end{tabular}

available in the circle. More precisely, five seismic domains are considered: eastern Alps, western Alps, northern Apennines, central Apennines, and southern Apennines (Figs. 2 and 3). A 100-km search radius was applied in the eastern Alps, a 200-km radius in the western Alps and northern Apennines, and a $300-\mathrm{km}$ radius in the rest of Italy. This approach is based on that applied by Ward (2007) in California. The maximum geodetic strain rate was translated into geodetic $M_{0} R$ at the same station locations by the application of the Kostrov's (1974) formula, considering the volume to which that strain rate is related. This passage from strain rate to $M_{0} R$ is not trivial. In fact, the mean strain rate $\varepsilon^{\prime}$ is equal to the sum of the moment $\left(M_{0}\right)$ tensors of all earthquakes occurring per unit time $t$ in a unit volume $V[V=$ $A H$, where $A$ is the area and $H$ is the seismogenic thickness; Kostrov (1974)], and is given by:

$\dot{\varepsilon}=\frac{\sum M_{0}}{2 \mu V \Delta t}$

in which $\mu$ is the shear modulus. The crustal volume is obviously a crucial parameter. In our case, the average surface geodetic strain rate is computed considering a circle of $100-$ to $300-\mathrm{km}$ radius and, consequently, it is assumed to represent the volumetric strain for the seismogenic zone beneath that circle. Equation 1 should define the 


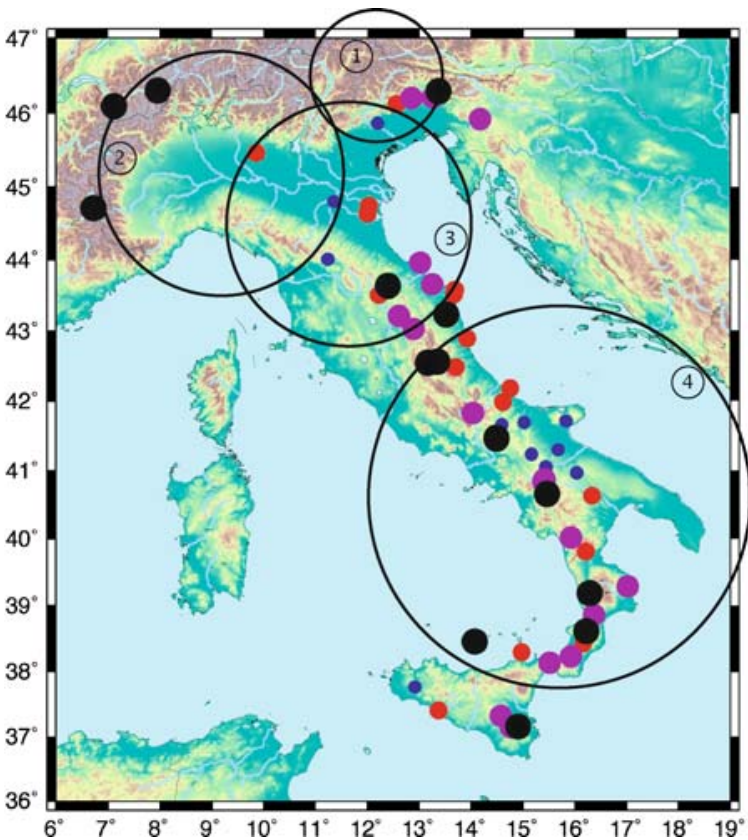

Fig. $3 M_{0} R$ (in N.m/year) computed by geophysical modelling for the seismogenic areas. Blue small dots for $M_{0} R<$ $5.0 \times 10^{15}$; red medium dots $5.0 \times 10^{15} \leq M_{0} R<1.0 \times$ $10^{16}$; purple medium circles $1.0 \times 10^{16} \leq M_{0} R<3.0 \times$ $10^{16}$; black large circles $M_{0} R \geq 3.0 \times 10^{16}$. The numbered large circles identify the four domains: 1 eastern Alps, 2 western Alps, 3 central Apennines, 4 southern Apennines

surface strain rate which can be accommodated in earthquake production in the volume $V$. A similar definition of the strain volume was already applied by Ward $(1994,1998)$ and Savage and Simpson (1997), although these authors considered the area to be limited strictly by the GPS stations, while our circles are slightly larger. We adopt an average value of $10 \mathrm{~km}$ for the seismogenic thickness because the majority of earthquakes in Italy do not exceed this depth. A shear modulus of $3.5 \times 10^{10} \mathrm{~N} / \mathrm{m}^{2}$ is also adopted. The resulting estimates of regional $M_{0} R$ from GPS geodesy show a considerable range across the different stations within a given domain (see Fig. 2); for example, in the eastern Alps the $M_{0} R$ of different stations varies between $0.03 \times 10^{18}$ and $2.12 \times 10^{18} \mathrm{~N} \cdot \mathrm{m} /$ year. The $M_{0} R$ of the central station in each domain was chosen as the $M_{0} R$ of the whole domain (see Table 2).

Considering the approximations and uncertainties introduced in the method above, we use an additional data set in our analyses. This second data set comes from finite-element modelling conducted to address the misfits between model predictions and a large amount of neotectonic data for Italy (Barba 2007; Barba et al. 2008, 2009). In these studies, model predictions were compared to three independent data sets: geodetic horizontal velocities from temporary and permanent GPS stations (Serpelloni et al. 2002, 2007; Caporali 2007); stress regime data, based on relative stress magnitudes, and the directions of maximum horizontal compressive stress (Montone et al. 2004). The model incorporates faults and realistic rheology in a two-layer grid (crust and lithospheric mantle) with laterally varying seismogenic thickness, heat flow, and topography. The horizontal components of the momentum equation (Kong and Bird 1995) were solved to predict long-term horizontal velocities, anelastic strain rates, verti-

Table $2 M_{0} R$ s of the domains

\begin{tabular}{lllllrr}
\hline Domain & $\begin{array}{l}\text { Reference } \\
\text { station }\end{array}$ & $\begin{array}{l}\text { Search } \\
\text { ray }(\mathrm{km})\end{array}$ & SAN1 & $\begin{array}{l}M_{0} R 1 \\
(\mathrm{~N} \cdot \mathrm{m} / \text { year })\end{array}$ & $\begin{array}{r}\text { SAN2 } \\
M_{0} R 2 \\
(\mathrm{~N} \cdot \mathrm{m} / \mathrm{year})\end{array}$ \\
\hline E Alps & AFAL-Faloria & 100 & 10 & $0.56 \times 10^{18}$ & 5 & $1.01 \times 10^{17}$ \\
W Alps & PAVI-Pavia & 200 & 20 & $0.62 \times 10^{18}$ & 4 & $1.53 \times 10^{17}$ \\
N Apennines & MEDI-Medicina & 200 & 47 & $1.98 \times 10^{18}$ & 18 & $3.29 \times 10^{17}$ \\
S Apennines & TITO-Tito & 300 & 34 & $7.67 \times 10^{18}$ & 26 & $4.77 \times 10^{17}$ \\
\hline
\end{tabular}

The index 1 refers to the GPS observations, while the index 2 refers to the results of the geophysical modelling. $M_{0} R 1$ is computed for the reference station while $M_{0} R 2$ is given by the sum of the $M_{0} R$ s calculated by modelling for the seismogenic areas belonging to each domain. SAN1 represents the number of seismogenic areas inside the search circle and can be larger than the actual number of seismogenic areas inside the domain (the same seismogenic area can belong to more than one domain if it is located in the overlapping areas of search circles). SAN2 is the number of seismogenic areas inside the domain for which $M_{0} R$ was possible to compute by the geophysical modelling (no overlapping areas as the seismogenic areas are associated to the pertinent domain only) 
cally integrated stresses, and fault slip rates. Seismogenic areas were simplistically represented as a single fault trace in these prior studies. In our analysis, we compute the strain and slip rates on the model grid and transform them into $M_{0} R$ for the different seismogenic areas considering
Table 3 Strain rate $\left(\varepsilon^{\prime}\right)$ and moment rate $\left(M_{0} R 2\right)$, modelled for the seismogenic areas

\begin{tabular}{|c|c|c|c|c|c|}
\hline Source & Region & Lon. E & Lat. $\mathrm{N}$ & $\varepsilon^{\prime}$ (ns/year) & $\begin{array}{l}M_{0} R 2 \\
\left(\mathrm{~N} \cdot \mathrm{m} / \text { year } \cdot 10^{15}\right)\end{array}$ \\
\hline ITSA002 & Cent. South. Alps & 9.859 & 45.460 & 0.90 & 6.554 \\
\hline ITSA003 & Ripabottoni & 15.029 & 41.685 & 1.60 & 1.544 \\
\hline ITSA004 & Ascoli Satriano & 15.677 & 41.309 & 1.40 & 2.450 \\
\hline ITSA005 & Picerno-Massafra & 16.328 & 40.634 & 21.40 & 7.068 \\
\hline ITSA006 & Sciacca-Gela & 13.374 & 37.407 & 4.00 & 5.314 \\
\hline ITSA008 & Conero onshore & 13.668 & 43.506 & 7.80 & 6.391 \\
\hline ITSA010 & Copparo-Comacchio & 12.035 & 44.743 & 5.90 & 7.420 \\
\hline ITSA012 & Portomaggiore & 12.001 & 44.629 & 5.40 & 7.486 \\
\hline ITSA013 & Aremogna & 14.037 & 41.822 & 30.60 & 16.483 \\
\hline ITSA014 & South. Tyrrhenian & 14.072 & 38.460 & 6.90 & 53.857 \\
\hline ITSA015 & Crati Valley & 16.285 & 39.186 & 45.20 & 55.998 \\
\hline ITSA016 & Aspromonte & 15.516 & 38.133 & 118.90 & 16.699 \\
\hline ITSA017 & Scicli-Catania & 14.908 & 37.161 & 57.90 & 79.656 \\
\hline ITSA019 & Crotone-Rossano & 17.022 & 39.287 & 14.60 & 11.859 \\
\hline ITSA020 & Southern Marche & 13.523 & 43.229 & 13.50 & 46.704 \\
\hline ITSA021 & Marsala-Belice & 12.921 & 37.764 & 5.30 & 2.142 \\
\hline ITSA024 & Castelpetroso & 14.487 & 41.468 & 51.30 & 60.454 \\
\hline ITSA025 & In. C. Apennines & 13.166 & 42.543 & 29.10 & 49.059 \\
\hline ITSA027 & Out. C. Apennines & 12.401 & 43.630 & 12.50 & 30.959 \\
\hline ITSA028 & Colfiorito & 12.889 & 43.024 & 81.60 & 15.391 \\
\hline ITSA029 & Gela-Catania & 14.577 & 37.324 & 63.60 & 28.045 \\
\hline ITSA031 & Conero offshore & 13.687 & 43.578 & 7.50 & 8.296 \\
\hline ITSA032 & Pesaro-Senigallia & 13.251 & 43.650 & 4.00 & 18.134 \\
\hline ITSA033 & Mt. Pollino South & 16.215 & 39.809 & 22.40 & 8.153 \\
\hline ITSA034 & Irpinia & 15.464 & 40.663 & 37.40 & 54.261 \\
\hline ITSA035 & Ragusa-Palagonia & 14.766 & 37.151 & 13.90 & 18.460 \\
\hline ITSA037 & Mugello & 11.237 & 44.004 & 23.60 & 4.128 \\
\hline ITSA038 & Mercure Basin & 15.929 & 40.015 & 39.70 & 25.133 \\
\hline ITSA040 & Castelluccio & 13.350 & 42.561 & 28.40 & 57.716 \\
\hline ITSA041 & Selci Lama & 12.226 & 43.502 & 37.60 & 8.261 \\
\hline ITSA042 & Patti-Eolie & 14.974 & 38.298 & 30.40 & 9.523 \\
\hline ITSA043 & Pesaro-Senigallia & 13.019 & 43.955 & 7.00 & 10.580 \\
\hline ITSA051 & Mirandola & 11.354 & 44.801 & 3.10 & 4.685 \\
\hline ITSA053 & Southern Calabria & 16.220 & 38.616 & 79.70 & 37.045 \\
\hline ITSA054 & Porto San Giorgio & 13.924 & 42.889 & 13.70 & 8.434 \\
\hline ITSA055 & Bagnara & 15.928 & 38.233 & 15.70 & 15.197 \\
\hline ITSA056 & Gubbio Basin & 12.611 & 43.210 & 59.40 & 23.835 \\
\hline ITSA057 & Pago Veiano & 15.163 & 41.238 & 7.30 & 2.808 \\
\hline ITSA058 & Mattinata & 15.830 & 41.710 & 1.30 & 0.969 \\
\hline ITSA059 & Tremiti & 14.757 & 42.180 & 2.20 & 5.313 \\
\hline ITSA060 & Montello & 12.202 & 45.864 & 15.90 & 4.273 \\
\hline ITSA061 & Cansiglio & 12.558 & 46.117 & 16.20 & 8.883 \\
\hline ITSA062 & Maniago-Sequals & 12.850 & 46.202 & 14.60 & 25.187 \\
\hline ITSA063 & Andretta-Filano & 15.415 & 40.874 & 49.10 & 26.406 \\
\hline ITSA064 & Tramonti-Kobarid & 13.378 & 46.294 & 11.70 & 33.937 \\
\hline ITSA066 & Gemona-Tarcento & 13.265 & 46.210 & 28.20 & 19.751 \\
\hline ITSA068 & Catanzaro Trough & 16.365 & 38.861 & 30.22 & 24.122 \\
\hline ITSA075 & Pietracamela & 13.704 & 42.487 & 9.50 & 5.804 \\
\hline
\end{tabular}


Table 3 (continued)

\begin{tabular}{lllcrc}
\hline Source & Region & Lon. E & Lat. N & $\varepsilon^{\prime}(\mathrm{ns} /$ year $)$ & $\begin{array}{l}M_{0} R 2 \\
\left(\mathrm{~N} \cdot \mathrm{m} / \text { year } \cdot 10^{15}\right)\end{array}$ \\
\hline ITSA077 & Pescolanciano & 14.594 & 41.654 & 52.10 & 2.968 \\
ITSA079 & Campomarino & 14.612 & 41.986 & 4.30 & 6.424 \\
ITSA080 & Nicotera & 16.162 & 38.431 & 45.00 & 6.407 \\
ITSA084 & Vallata & 15.442 & 41.058 & 11.50 & 3.155 \\
ITSA087 & Conza-Tolve & 15.393 & 40.840 & 67.10 & 22.212 \\
ITSA089 & Melfi-Spinazzola & 16.036 & 40.969 & 1.70 & 0.972 \\
SISA002 & Tolmin-Idrija & 14.176 & 45.918 & 29.70 & 15.373 \\
\hline
\end{tabular}

the volume represented by the length, width, and thickness of crust represented by the seismogenic area. A combination of fault slip rate data (where available) and strain rate collectively accounts for known as well as unknown faults (see Table 3). Figure 3 shows the $M_{0} R$ s obtained for the seismogenic areas. We note that the transformation of strain rate into $M_{0} R$ by Eq. 1 is simplistic in the sense that it ignores the possibility that some of the geophysical strain rate may be released aseismically. We consider this issue specifically later in the paper.

Table 2 gives details about the $M_{0} R \mathrm{~s}$ in the domains. The index 1 of the table refers to the GPS observations, while the index 2 refers to the results of the geophysical modelling. In the case of the geodetic constraint, the domain $M_{0} R\left(M_{0} R 1\right.$ in Table 2$)$ corresponds to that calculated for the central GPS station and represents the sum of the $M_{0} R$ of each seismogenic area in the domain, plus the $M_{0} R$ of the distributed seismicity (earthquakes of $M_{\mathrm{W}}$ less than 5.5 and, consequently, outside the seismogenic areas), plus that released as aseismic creep. In the case of the geophysical constraint, the domain $M_{0} R\left(M_{0} R 2\right.$ in Table 2) is given by the sum of the $M_{0} R$ s of the seismogenic areas calculated by the geophysical modelling. In the case of the geodetic constraint, the number of seismogenic areas inside the search circle (SAN1 in Table 2) can be larger than the actual number of seismogenic areas inside the domain because the same seismogenic area can belong to more than one domain if it is located in the overlapping areas of search circles. As it was not possible to compute the $M_{0} R$ by the geophysical modelling for all the seismogenic areas, the number of seismogenic areas inside a domain in the case of the geophysical constraint (SAN2 in
Table 2) can be less than the actual number of seismogenic areas inside that domain defined in the Database of the Italian Seismogenic Sources. This explains the differences between the numbers in Table 2 and what shown by Figs. 2 and 3 .

Figure 2 displays the $M_{0} R \mathrm{~s}$ calculated for the GPS stations from the geodetic observations (circles): the squares highlight the reference stations, whose $M_{0} R$ s are associated to the domain $\left(M_{0} R 1\right.$ in Table 2) and used as input data in the following computations. The circles in Fig. 3 quantify the $M_{0} R$ computed by the geophysical modelling for each seismogenic area: the sum of the $M_{0} R$ s inside each domain gives the value reported in Table $2\left(M_{0} R 2\right)$. A direct comparison between the $M_{0} R$ estimates obtained with the two different methods is not possible. In fact, according to the geodetic constraints, the value reported in Table 2 overestimates the $M_{0} R$ of the domain because some seismogenic areas are counted more than once as they appear in several domains, depending on the overlapping of the search radii. According to the geophysical constraints, the value reported in Table 2 underestimates the $M_{0} R$ of the domain because it is not possible to compute the strain rate (and, consequently, the $M_{0} R$ ) for all the seismogenic areas by the geophysical modelling. The two estimates differ by a factor from 5 to 12 , and those calculated with geodetic constraints are higher than those computed by the geophysical modelling (see Table 2). This discrepancy is motivated by the fact that the $M_{0} R$ in each domain from GPS observations is given by the sum of the $M_{0} R$ released as characteristic earthquakes plus that released as distributed seismicity and as aseismic creep, while the $M_{0} R$ from geophysical modelling refers only to the contribution of the characteristic earthquakes. 


\section{Comparison of moment rate derived from geodetic and seismicity data}

To compare the observed geodetic moment rate $\left(M_{0} R 1\right)$ with the seismic one, domain catalogues have been extracted from the Italian earthquake catalogue (Gruppo di lavoro CPTI 2004). These catalogues collect all the events in a circle centered on the reference GPS stations (Faloria,
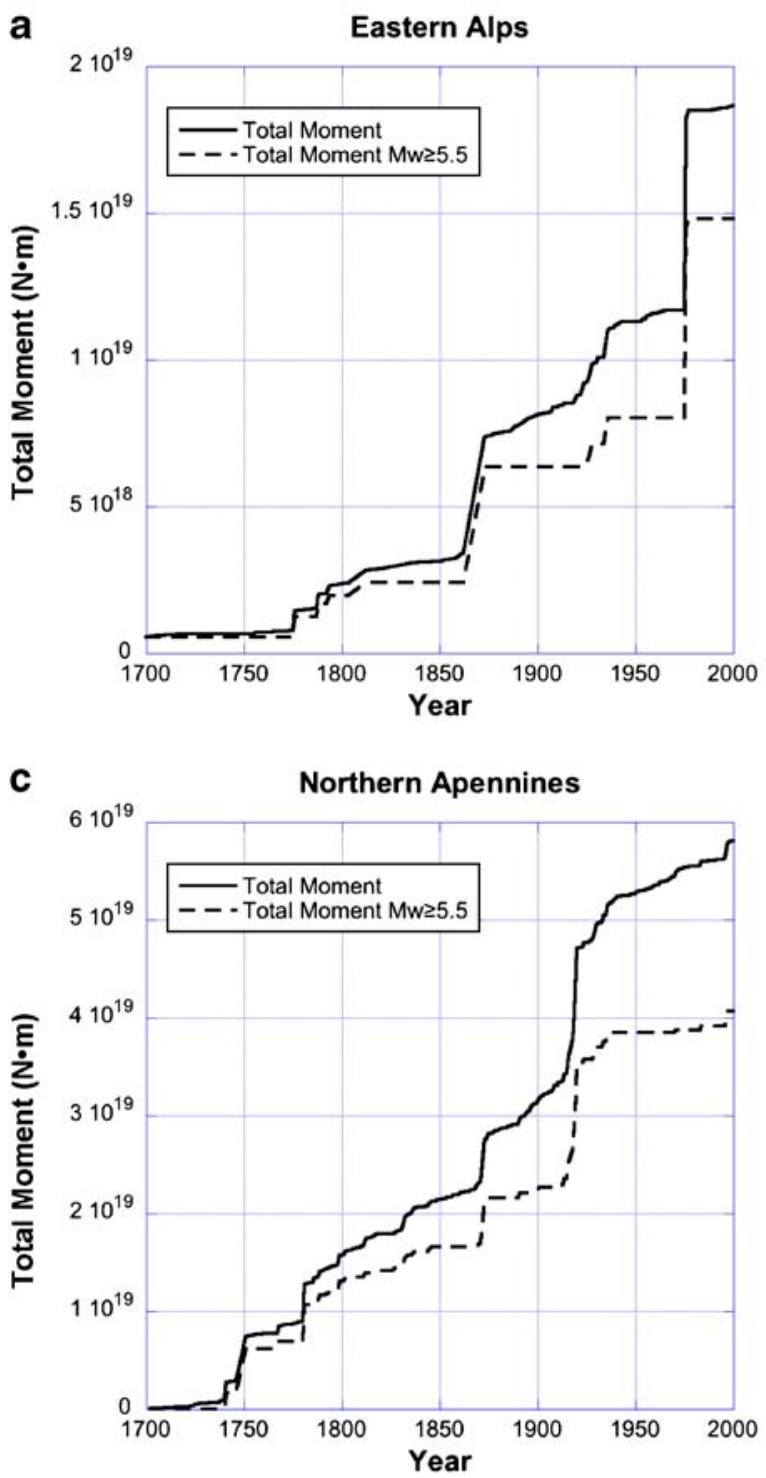

Fig. $4 M_{0}$ release since 1700 in the four domains: a eastern Alps, b western Alps, c northern Apennines, d southern Apennines. Solid line for all earthquakes of the Italian
Pavia, Medicina, and Tito) and with the same radius as that used for the computation of $M_{0} R 1$ : $100 \mathrm{~km}$ for Faloria, $200 \mathrm{~km}$ for Pavia and Medicina, and $300 \mathrm{~km}$ for Tito. The observed seismic moment rate $\left(M_{0} R_{\text {oss }}\right)$ in each of the four domains has been computed considering all the earthquakes which have occurred since the beginning of the eighteenth century, because this period can be considered complete for $M_{\mathrm{W}} 5.5$ and
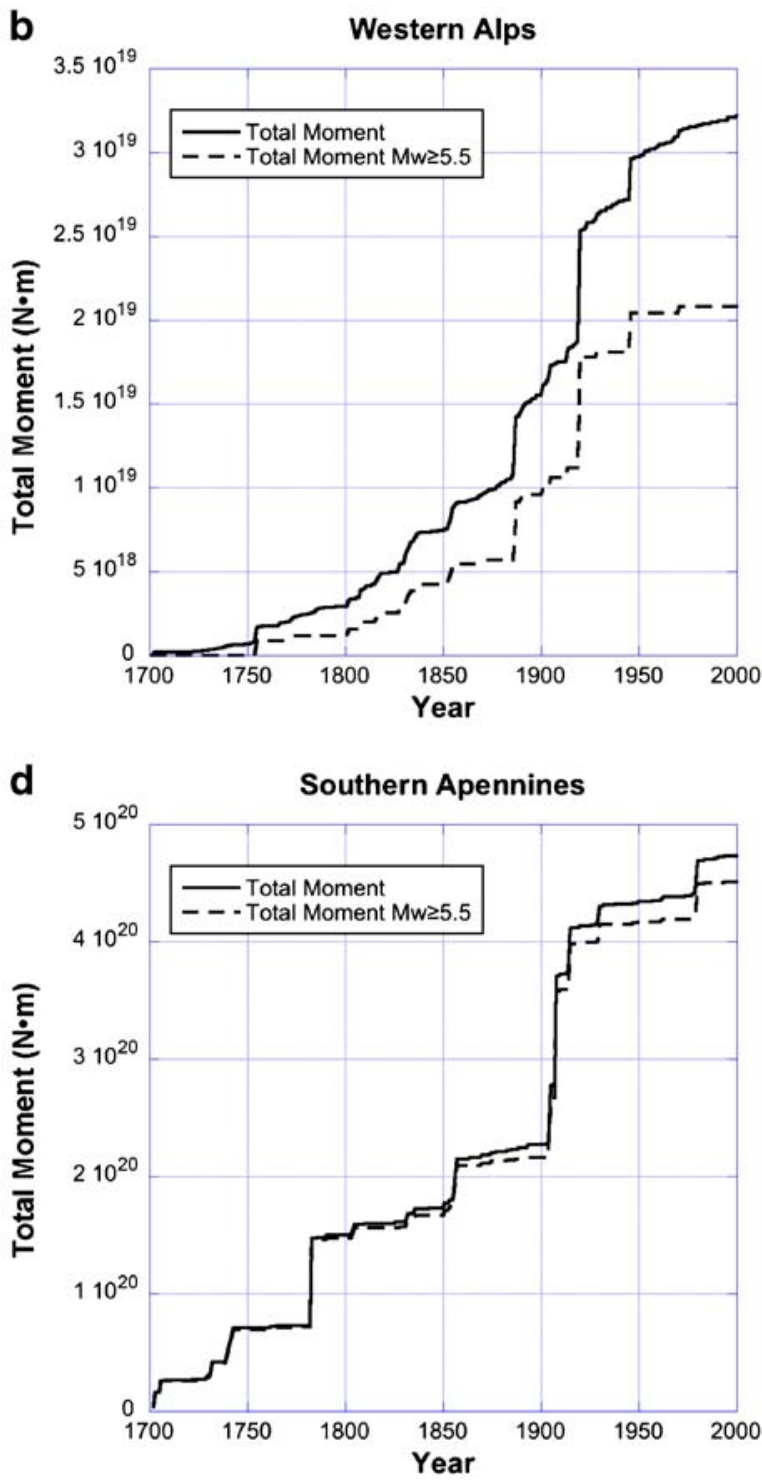

earthquake catalogue (Gruppo di lavoro CPTI 2004), dashed line for events with an $M_{\mathrm{W}} 5.5$ and over. The vertical scale varies in the different panels 
over. The Hanks and Kanamori (1979) relation was used to compute seismic moment from $M_{\mathrm{W}}$ and the observed seismic moment rate of events with $M_{\mathrm{W}} 5.5$ and over $\left(M_{0} R_{\mathrm{oss} 5.5}\right)$ was computed as well (Fig. 4).

As the above $M_{0} R_{\text {oss }}$ does not represent the total seismic moment rate, the Gutenberg-Richter relation was calculated for the four domains. First, the seismicity rates for each magnitude class were computed by the Albarello and Mucciarelli (2002) approach, where the whole catalogue is divided into time intervals for each of which the probability that it is complete is evaluated and the related rate is weighted accordingly. The Gutenberg-Richter parameters ( $a$ and $b$ values) were calculated by the application of the maximum likelihood approach according to the Weichert (1980) procedure. From the GutenbergRichter distribution, the individual annual rates were derived and, from them and the $M_{\mathrm{W}} \mathrm{s}$ (from the maximum observed magnitude to 0.1$)$, the calculated seismic moment rate $\left(M_{0} R_{\text {cal }}\right)$ was obtained. As this $M_{0} R_{\text {cal }}$ was calculated considering all the $M_{\mathrm{W}} \mathrm{s}$, it should represent the actual seismic moment rate released by each domain. In addition, the computed seismic moment rate for events with $M_{\mathrm{W}} 5.5$ and over $\left(M_{0} R_{\mathrm{cal} 5.5}\right)$ was also computed. It can be seen from Table 4 , where all the results are reported, that the $M_{0} R_{\text {cal }}$ is larger than the $M_{0} R_{\text {oss }}$ and the difference varies from one domain to the other from less than two times in the eastern Alps to more than three times in the western Alps. It is notable the situation of the southern Apennines, where $M_{0} R_{\mathrm{oss}}$ is larger than $M_{0} R_{\text {cal }}$ because of the large number of moderate-to-large earthquakes which occurred there in the last three centuries. Increasing the time period over which the calculation is done the value of $M_{0} R_{\text {oss }}$ decreases notably (e.g.: it is $12.0 \times 10^{17}$ when calculated considering the last five centuries). Moreover, it is quite interesting to observe which is the contribution in terms of $M_{0} R_{\text {cal }}$ given by the strong earthquakes $\left(M_{\mathrm{W}} 5.5\right.$ and over) in each domain. Also in this case the ratio spans over a large interval: strong earthquakes contribute largely in the eastern Alps and in the southern Apennines, where their presence is frequent, while their contribution is limited in the other two domains.

The final comparison refers to the ratio between $M_{0} R_{\text {cal }}$ and $M_{0} R 1$ and quantifies the amount of strain which is supposed to be released seismically. This ratio is quite constant around $20-30 \%$ with the exception of the western Alps, where it is about $60 \%$. Bressan and Bragato (2009) have found that a significant part of the deformation occur aseismically in the eastern Alps.

In summary, the comparison among the three estimates of $M_{0} R$ shows that: (1) $M_{0} R_{\text {cal }}$ is much larger than $M_{0} R_{\text {oss }}$, with the exception of the southern Apennines; (2) $M_{0} R 1$ is larger (about four times) than $M_{0} R_{\text {cal }}$, with the exception of the western Alps. These values will be introduced in the following computations. More precisely, the part of the $M_{0} R$ which is supposed to be released aseismically (obtained from $M_{0} R_{\mathrm{cal}} / M_{0} R 1$ in Table 4) will be subtracted from $M_{0} R 1$ in the analysis that refers to the domains. The ratio between the total moment rate from the finite element model and the seismic moment rate for $M_{\mathrm{w}} \geq 5.5$ is 1.06 . So, this correction is applied, subtracting $6 \%$ from $M_{0} R 2$ in the analysis referring to the seismogenic areas. The $M_{0} R$ that refers to the distributed seismicity (events with an

Table 4 Annual $M_{0} R \mathrm{~s}$ (in N.m/year) and $b$ values (with related standard deviation) for the four domains

\begin{tabular}{llllllllll}
\hline Domain & $b$ & $\sigma b$ & $\begin{array}{l}M_{0} R 1 \\
\left(\times 10^{17}\right)\end{array}$ & $\begin{array}{l}M_{0} R_{\mathrm{OSs}} \\
\left(\times 10^{17}\right)\end{array}$ & $\begin{array}{l}M_{0} R_{\mathrm{Oss} 5.5} \\
\left(\times 10^{17}\right)\end{array}$ & $\begin{array}{l}M_{0} R_{\mathrm{cal}} \\
\left(\times 10^{17}\right)\end{array}$ & $\begin{array}{l}M_{0} R_{\mathrm{cal} 5.5} \\
\left(\times 10^{17}\right)\end{array}$ & $\begin{array}{l}M_{0} R_{\mathrm{ca} 5.5} \\
/ \mathrm{M}_{0} R_{\mathrm{cal}}\end{array}$ & $\begin{array}{l}M_{0} R_{\mathrm{cal}} \\
/ \mathrm{M}_{0} R 1\end{array}$ \\
\hline E Alps & 1.13 & 0.15 & 5.6 & 0.62 & 0.49 & 1.17 & 0.85 & 0.73 & 0.21 \\
W Alps & 1.50 & 0.13 & 6.2 & 1.07 & 0.69 & 3.89 & 0.70 & 0.18 & 0.63 \\
N Apen. & 1.44 & 0.10 & 19.8 & 1.93 & 1.35 & 5.33 & 1.63 & 0.31 & 0.27 \\
S Apen. & 1.09 & 0.06 & 76.7 & 15.7 & 14.9 & 14.5 & 9.37 & 0.85 & 0.19 \\
\hline
\end{tabular}

$M_{0} R 1$ is the geodetic value (see Table 2), $M_{0} R_{\text {oss }}$ is the value observed in the last three centuries (see Fig. 4 ) according to the Italian earthquake catalogue (Gruppo di lavoro CPTI 2004), $M_{0} R_{\mathrm{Oss} 5.5}$ is the same as $M_{0} R_{\mathrm{Oss}}$ but referring to earthquakes with an $M_{\mathrm{W}} 5.5$ and over, $M_{0} R_{\mathrm{cal}}$ is the value calculated from the Gutenberg-Richter relation for all $M_{\mathrm{W}} \mathrm{s}, M_{0} R_{\mathrm{cal}} .5$ is the same as $M_{0} R_{\text {cal }}$ but calculated for earthquakes with an $M_{\mathrm{W}} 5.5$ and over 
$\left.M_{\mathrm{W}}<5.5\right)$, which is not considered in $M_{0} R 2$ (Barba, personal communication), can be calculated from the ratio between the $M_{0} R$ released by large earthquakes and that released by all earthquakes $\left(M_{0} R_{\mathrm{cal} 5.5} / M_{0} R_{\mathrm{cal}}\right.$ in Table 4$)$ and it is added to $M_{0} R 2$ before the computations. Conversely, $M_{0} R 1$ does not need any addiction, as it is comprehensive of the earthquakes of all magnitude. As the geophysical model is satisfactorily constrained only for the Apennines, we will restrict the following elaborations only to the seismogenic areas along the Apennines.

\section{Definition of faults inside the seismogenic areas}

Our knowledge of the seismogenic faults in Italy is far from complete. Hence an ability to account for unmapped faults in seismic hazard models is highly advantageous. Seismogenic areas in Italy are often empty (no mapped faults within) or partially filled with mapped faults. A statistical procedure was developed by Stirling et al. (2007) to fill the empty space of the seismogenic areas with modelled faults with parameters equivalent to those of the mapped faults. The procedure for defining the modelled faults is of Monte Carlo type, and therefore takes account of all the uncertainties in parameters from the mapped faults. In the end, a distribution of modelled fault source parameters is defined, enabling probabilities of specific rupture parameters to be obtained from the distribution.

Entering into detail, each of the four domains contains a certain number of seismogenic areas. Each seismogenic area contains a certain number of mapped faults; the empty space is the difference between the length of the seismogenic area and the sum of the lengths of the mapped faults. This empty space is filled by modelled faults, whose dimensions are simplistically assumed to mimic those [mean and standard deviation $(\sigma)$ ] of the mapped faults present in the domain. The average value of the length of the mapped faults in each domain is, then, considered representative also of the length of the modelled faults in that domain, and the length of these modelled faults is allowed to vary in the range given by the average length of the mapped faults $\pm 1 \sigma$. The procedure for filling each empty space of the seismogenic areas is of the Monte Carlo type, in our case with 1,000 repetitions. The algorithm samples the rupture length repeatedly and randomly between the minimum (mean $-1 \sigma$ ) and maximum (mean $+1 \sigma$ ) values, and each sample is used to calculate a set of realistic earthquake rupture lengths that fill the empty space of the seismogenic area. The rupture lengths are assumed to be positioned endon-end, meaning that no overlapping ruptures are assumed. A random number generator producing uniformly distributed random numbers between 0 and 1 [subroutine Random 1 in Press et al. (1992)] was the basis for sampling the range, using the extreme endpoints $\pm 1-\sigma$ values for sampling the average rupture.

In the end, we obtain a set of modelled faults, which mimic the distribution of the mapped faults and fill the empty space of each seismogenic area of each domain.

The number of faults of a specific rupture length in each seismogenic area is given, then, by the sum of the numbers of mapped $\left(N 1_{i}\right)$ and modelled $\left(N 2_{i}\right)$ faults, and the total number of faults of a specific rupture length in each domain $\left(N_{i}^{*}\right)$ is obtained summing up the number of faults in each seismogenic area:

$N_{i}^{*}=\sum_{j=1}^{N_{S A}}\left(N 1_{i_{j}}+N 2_{i_{j}}\right)$

where $N_{S A}$ is the number of seismogenic areas in the considered domain.

An example of the approach followed for the definition of the modelled faults and the associated parameters is shown for the eastern Alps domain in Table 5 and Fig. 5. This domain contains eight seismogenic areas (purple boxes in Fig. 5a), each of which can or cannot contain mapped faults (red boxes in Fig. 5a); the number of mapped faults in each seismogenic area is reported in Table 5 according to its characteristic magnitude derived by its rupture length (Wells and Coppersmith 1994).

The mean length of the mapped faults is $11.96 \mathrm{~km}$ with a $\sigma$ of $4.65 \mathrm{~km}$. After the Monte Carlo simulations, the resulting number of modelled faults is reported in Table 5. Figure 5b shows the combined result for the modelled and mapped 
Table 5 Number of mapped and modelled faults in the eastern Alps domain

\begin{tabular}{|c|c|c|c|c|c|c|c|c|c|c|c|c|c|c|c|c|c|c|}
\hline \multirow[t]{2}{*}{$M_{W}$} & \multicolumn{2}{|c|}{ SA_007 } & \multicolumn{2}{|c|}{ SA_060 } & \multicolumn{2}{|c|}{ SA_061 } & \multicolumn{2}{|c|}{ SA_062 } & \multicolumn{2}{|c|}{ SA_064 } & \multicolumn{2}{|c|}{ SA_065 } & \multicolumn{2}{|c|}{ SA_066 } & \multicolumn{2}{|c|}{ SA_067 } & \multicolumn{2}{|l|}{ Total } \\
\hline & Mod. & M. & Mod. & M. & Mod. & M. & Mod. & M. & Mod. & M. & Mod. & M. & Mod. & M. & Mod. & M. & Mod. & M. \\
\hline 5 & 0.000 & 1 & 0.000 & 0 & 0.000 & 0 & 0.000 & 0 & 0.000 & 0 & 0.000 & 0 & 0.000 & 0 & 0.000 & 0 & 0.000 & 1 \\
\hline 5.6 & .000 & 0 & 0.000 & 0 & 0.000 & 0 & 0.000 & 0 & 0.000 & 0 & 0.000 & 0 & 0.000 & 0 & 0.000 & 0 & 0.000 & 0 \\
\hline 5.7 & 0.000 & 0 & 0.000 & 0 & 0.000 & 0 & 0.000 & 0 & 0.000 & 0 & 0.000 & 0 & 0.000 & 1 & 0.000 & 0 & 0.000 & 1 \\
\hline 5.8 & 0.000 & 0 & 0.000 & 0 & 0.000 & 0 & 0.000 & 0 & 0.000 & 1 & 0.069 & 0 & 0.000 & 0 & 0.181 & 0 & 0.250 & 1 \\
\hline 5.9 & 0.000 & 0 & 0.000 & 0 & 0.000 & 0 & 0.000 & 1 & 0.306 & 0 & 0.267 & 0 & 0.000 & 0 & 0.263 & 0 & 0.836 & 1 \\
\hline 6.0 & 0.256 & 0 & 0.015 & 0 & 0.127 & 0 & 0.000 & 0 & 0.826 & 0 & 0.250 & 0 & 0.000 & 1 & 0.270 & 0 & 1.744 & 1 \\
\hline 6.1 & 0.606 & 0 & 0.182 & 1 & 0.238 & 1 & 0.000 & 0 & 0.977 & 0 & 0.332 & 0 & 0.000 & 0 & 0.299 & 0 & 2.634 & 2 \\
\hline 6.2 & 0.138 & 0 & 0.302 & 0 & 0.283 & 0 & 0.000 & 0 & 1.047 & 0 & 0.083 & 0 & 0.000 & 0 & 0.122 & 0 & 1.975 & 0 \\
\hline 6.3 & 0.000 & 0 & 0.319 & 0 & 0.326 & 0 & 0.000 & 0 & 0.355 & 0 & 0.000 & 0 & 0.000 & 0 & 0.000 & 0 & 1.000 & 0 \\
\hline 6.4 & 0.000 & 0 & 0.260 & 1 & 0.054 & 0 & 0.000 & 0 & 0.000 & 0 & 0.000 & 1 & 0.000 & 0 & 0.000 & 0 & 0.314 & 2 \\
\hline 6.5 & 0.000 & 0 & 0.062 & 1 & 0.000 & 0 & 0.000 & 1 & 0.000 & 0 & 0.000 & 0 & 0.000 & 1 & 0.000 & 0 & 0.062 & 3 \\
\hline 6.6 & 0.000 & 2 & 0.000 & 0 & 0.000 & 0 & 0.000 & 0 & 0.000 & 0 & 0.000 & 0 & 0.000 & 0 & 0.000 & 0 & 0.000 & 2 \\
\hline
\end{tabular}

The number of seismogenic areas refers to Fig. 5a.

Mod. indicates the modelled faults (i.e.: resulting number from the Monte Carlo simulations divided by 1000), $M$. the mapped ones

fault sources. The distribution of the modelled faults shows a Gaussian pattern with central tendency around magnitude 6.1. The number of modelled faults is larger than that of the mapped faults around magnitude 6.1 while it is minimal at the edges of the distribution. Some peculiar features are given by the number of mapped faults: no faults referring to magnitude 6.2 and 6.3 have been identified yet in this domain while the number of those of exceeding magnitude 6.4 and larger is notable.

\section{Geodetic constraints on seismicity rates}

Our approach is to convert $M_{0} R$ for each domain into earthquake magnitude and frequency. The earthquakes are assumed to be described by the a

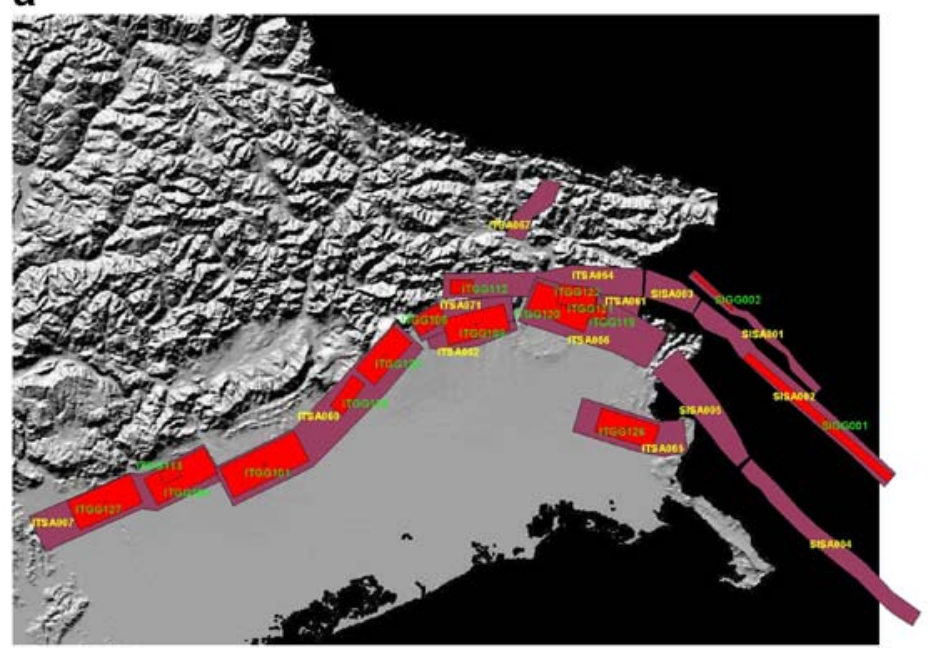

b

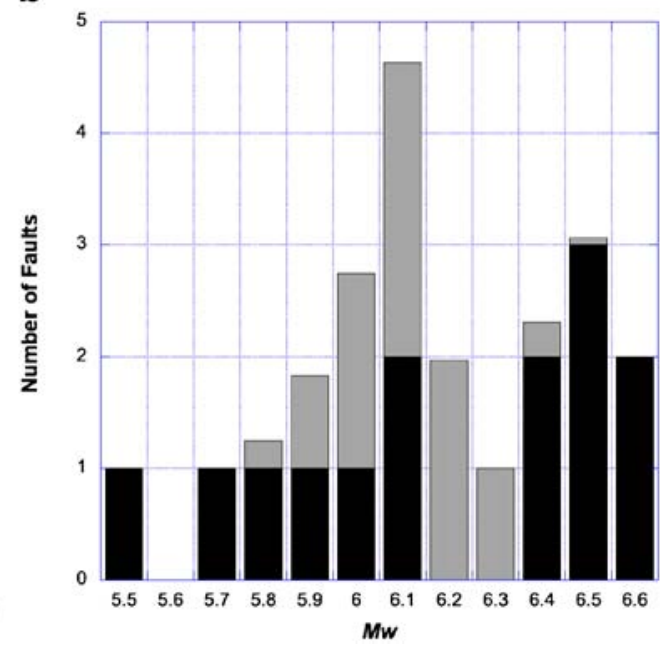

Fig. 5 Mapped and modelled faults in the eastern Alps domain: a seismogenic areas (purple areas marked by ITSA) and mapped faults (red areas marked by ITGG), b magnitude distribution (black columns for the mapped faults and grey columns for the modelled faults) 
characteristic earthquake model on a given fault, and these characteristic earthquakes collectively describe a Gutenberg-Richter distribution at a regional scale (i.e. within each domain, or Italy as a whole). We also calculate distributed earthquake recurrence parameters for each domain from a combination of catalogue seismicity and geodetic observations. Gutenberg-Richter $b$ values of each domain are computed from the seismicity observed in the domain itself, while the $a$ value of each domain can be obtained from the geodetic observations, i.e. from the $M_{0} R$ in the domain. In fact,

$\log N^{\prime}=a^{\prime}-b^{\prime} \log M_{0}$

where $N^{\prime}$ is the number of earthquakes with seismic moment larger than, or equal to, $M_{0}$, where

$a^{\prime}=a+\frac{9.1}{1.5} b$

and

$b^{\prime}=\frac{1}{1.5} b$

considering the relation between magnitude, $M_{\mathrm{W}}$, and $M_{0}$ in N.m (Hanks and Kanamori 1979):

$\log M_{0}=9.1+1.5 M_{\mathrm{W}}$

Knowing the value of the $M_{0} R$ in the domain under study, in our case obtained from the geodetic observations, and fixing the maximum value for $M_{0}$, derived from the maximum magnitude for that domain, we can write:

$M_{0} R=\sum_{i} N_{i} M_{0_{i}}$

where $N_{i}$ is the unknown annual non-cumulative number of earthquakes with $M_{0 i}$, and the index $i$ represents all the classes of $M_{0}$ in the domain.

From Eq. 3 we have

$N_{i}^{\prime}=10^{a^{\prime}-b^{\prime} \log M_{0_{i}}}$

where $N_{i}^{\prime}$ is the cumulative number of earthquakes with $M_{0 i}$ and above.
From the cumulative number we can compute the non-cumulative number $N_{i}$ :

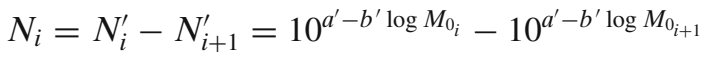

$$
\begin{aligned}
& =10^{a^{\prime}}\left(\frac{1}{10^{b^{\prime} \log M_{0_{i}}}}-\frac{1}{10^{b^{\prime} \log M_{0_{i+1}}}}\right)
\end{aligned}
$$

Substituting the value of $N_{i}$ given by Eq. 9 into Eq. 7, we obtain an equation where the only unknown term is the $a^{\prime}$ value. In such a way we can compute the $a^{\prime}$ value in the domain under study from strain instead of from seismicity and, consequently, we can obtain the $a$ value from Eq. 4, and the number of earthquakes, $N_{i}$, for all classes of seismic $M_{0 i}$ from Eq. 9.

In agreement with the identification of faults (mapped and modelled) inside the seismogenic areas introduced in the previous section and considering the existing equivalence between $M_{0}$ and fault rupture length, obtained by the application of the Wells and Coppersmith (1994) and Hanks and Kanamori (1979) scaling laws, in each domain, the number of earthquakes, $N_{i}$, of a specific class of $M_{0 i}$ is given by the product of the number of faults of a given rupture length $\left[N_{i}^{*}\right.$ in Eq. 2] and the related rate of occurrence, $v_{i}$

$N_{i}=N_{i}^{*} \cdot v_{i}$

In such a way, we can compute the rate of occurrence for each class of $M_{0}$. This rate will determine a regional Gutenberg-Richter distribution (i.e.: in the domain), while the Gutenberg-Richter distribution will not be reflected inside the seismogenic areas.

In summary, our procedure defines a suite of mapped and modelled fault sources inside each seismogenic area, each with a defined fault source length and, consequently, with a characteristic $M_{0}$. From the $M_{0} R$ obtained from geodetic observations, we constrain the occurrence rate for each class of $M_{0}$. The earthquake recurrence for fault sources within seismogenic areas is defined according to the characteristic earthquake model, and the distributed seismicity parameters for the surrounding domains are modelled according to the Gutenberg-Richter relationship. 


\section{Geophysical constraints on seismicity rates}

We also use strain rates produced through numerical modelling by Barba (2007). Such strain rates are those corresponding to the least misfit between geodetic (Caporali 2007; Serpelloni et al. 2007) and stress data (Montone et al. 2004) and the numerical predictions produced by trialand-error, using thin-shell finite element code SHELLS (Bird 1999), in a large number of iterations which mostly differ by boundary conditions, fault friction coefficient [as for example in Barba et al. $(2008,2009)]$.

The technique gives a value of the $M_{0} R$ for each seismogenic area and, consequently, the computation refers to each seismogenic area instead of to each domain. In the geodetic constraint approach the characteristic earthquakes of the mapped and modelled faults form a GutenbergRichter distribution in the domains but not necessarily inside the seismogenic areas. Differently, in the geophysical constraint approach, the characteristic earthquakes of the mapped and modelled fault sources defined inside each seismogenic area collectively produce a Gutenberg-Richter distribution. The observation of a Gutenberg-Richter distribution for large regions, countries, and the globe is well documented (e.g. WGCEP 1995; Stirling et al. 1998).

\section{Application}

As a working hypothesis it is assumed that only earthquakes with $M_{\mathrm{W}} 5.5$ and above occur in the seismogenic areas, and while the $M_{0} R$ calculated from geodetic observations represents the regional total value (i.e.: earthquakes in the seismogenic areas plus distributed seismicity plus aseismic creep), the $M_{0} R$ obtained from the geophysical modelling refers to the seismicity of the seismogenic areas only. In the geodetic constraint case, the percentage of $M_{0} R$ accommodated as an aseismic creep was taken from Table 4 (column 10), while the distributed seismicity is represented by the Gutenberg-Richter relation for events of $M_{\mathrm{W}}$ less than 5.5. [Eq. 7 applies to the whole range of $M_{0}$ (i.e., $M_{\mathrm{W}}$ in the range $0-M_{\max }$ ) although only events related to $M_{\mathrm{W}} 5.5$ and larger are treated in the computation of probabilities]. In the geophysical modelling case, the percentage of moment rate related to the distributed seismicity is derived from Table 4 (column 9) and added to the value calculated from the modelling (that refers only to events with an $M_{\mathrm{W}} 5.5$ and larger). In both cases a regional $b$ value is assumed for the earthquake rate calculations (see Table 4). The Poisson distribution is then used to estimate the probability of exceeding magnitude $m$ in $t$ years, $F_{M t}(m)$ :

$F_{M_{t}}(m)=P\left[M_{t}>m\right]=1-e^{-v t}$

where $v$ is the annual rate of magnitude $m$ and over. This approach is applied to four domains covering Italy and for which the regional $M_{0} R$ can be computed. The number of events for each $M_{0}$ class was determined according to Eq. 10 and it was then scaled in the seismogenic areas according to Eq. 2. The cumulative rate for each magnitude class is obtained in such a way, and the associated probabilities were computed for exceeding different magnitude classes inside each seismogenic area.

The approach based on the geophysical constraints was applied directly considering the seismogenic areas.

\section{Results}

We show our 30-year probability for $M_{\mathrm{W}} \geq 6.0$ and $\geq 6.5$ in Table 6 and Figs. 6 and 7, obtained by way of the geodetic constraints and derived from the geophysical modelling. It is interesting to note that there is no direct proportionality between the forecasts for $M_{\mathrm{W}} 6.0$ (Fig. 6) and 6.5 (Fig. 7): this is due to the fact that the seismogenic areas are supposed to be composed of faults which behave according to the characteristic earthquake model. Consequently, the probability distribution of each seismogenic area is strongly peaked at specific magnitude values, e.g.: the characteristic magnitudes of the faults existing there. A clear example is given by the probabilities of the two seismogenic 
Table 6 Exceedance probability in 30 years for magnitude 6.0 and 6.5

\begin{tabular}{|c|c|c|c|c|c|c|}
\hline SA ID & Lon. E & Lat. N & P1-6.0 & P1-6.5 & P2-6.0 & P2-6.5 \\
\hline CHSA001 & 7.974 & 46.301 & 0.014 & & & \\
\hline CHSA002 & 7.255 & 46.117 & 0.013 & & & \\
\hline FRSA001 & 6.655 & 44.706 & 0.013 & & & \\
\hline ITSA001 & 11.826 & 44.231 & 0.010 & 0.001 & & \\
\hline ITSA002 & 9.820 & 45.438 & 0.014 & 0.003 & 0.011 & 0.001 \\
\hline ITSA003 & 15.161 & 41.699 & 0.080 & 0.031 & 0.003 & 0.001 \\
\hline ITSA004 & 15.965 & 41.287 & 0.177 & 0.002 & 0.007 & \\
\hline ITSA005 & 16.333 & 40.642 & 0.051 & & 0.013 & \\
\hline ITSA007 & 11.690 & 45.766 & 0.031 & 0.014 & & \\
\hline ITSA008 & 13.578 & 43.541 & 0.007 & & 0.009 & \\
\hline ITSA009 & 10.270 & 44.824 & 0.014 & 0.001 & & \\
\hline ITSA010 & 12.035 & 44.743 & & & 0.015 & 0.002 \\
\hline ITSA011 & 12.045 & 44.348 & 0.011 & & & \\
\hline ITSA012 & 12.080 & 44.567 & 0.014 & 0.001 & 0.015 & 0.002 \\
\hline ITSA013 & 13.975 & 41.870 & 0.035 & & 0.023 & \\
\hline ITSA014 & 13.180 & 38.339 & 0.039 & 0.036 & 0.085 & 0.027 \\
\hline ITSA015 & 16.249 & 39.375 & 0.113 & & 0.097 & \\
\hline ITSA016 & 15.599 & 38.103 & 0.030 & 0.030 & 0.007 & 0.007 \\
\hline ITSA018 & 9.146 & 44.997 & 0.014 & 0.001 & & \\
\hline ITSA019 & 17.016 & 39.294 & 0.035 & 0.025 & 0.035 & 0.006 \\
\hline ITSA020 & 13.664 & 42.990 & 0.010 & & 0.084 & \\
\hline ITSA022 & 7.767 & 43.880 & 0.022 & 0.001 & & \\
\hline ITSA023 & 7.385 & 44.890 & 0.011 & & & \\
\hline ITSA024 & 14.605 & 41.382 & 0.085 & 0.054 & 0.130 & 0.017 \\
\hline ITSA025 & 13.382 & 42.263 & 0.044 & 0.035 & 0.100 & 0.014 \\
\hline ITSA026 & 10.150 & 44.299 & 0.040 & & & \\
\hline ITSA027 & 12.374 & 43.684 & 0.080 & 0.026 & 0.085 & 0.011 \\
\hline ITSA028 & 12.835 & 43.069 & 0.024 & & 0.022 & \\
\hline ITSA030 & 12.696 & 44.073 & & & & \\
\hline ITSA031 & 13.698 & 43.580 & 0.010 & & 0.015 & \\
\hline ITSA032 & 13.053 & 43.754 & 0.021 & & 0.030 & \\
\hline ITSA033 & 16.237 & 39.789 & 0.048 & & 0.016 & \\
\hline ITSA034 & 15.540 & 40.575 & 0.215 & 0.092 & 0.210 & 0.020 \\
\hline ITSA037 & 12.277 & 43.384 & 0.021 & & 0.008 & 0.001 \\
\hline ITSA038 & 15.954 & 40.040 & 0.086 & & 0.099 & 0.004 \\
\hline ITSA039 & 12.494 & 44.047 & 0.009 & & & \\
\hline ITSA040 & 13.427 & 42.460 & 0.039 & & 0.103 & \\
\hline ITSA041 & 12.178 & 43.547 & & & & \\
\hline ITSA042 & 14.990 & 38.309 & 0.094 & 0.029 & 0.033 & 0.004 \\
\hline ITSA043 & 13.145 & 43.877 & 0.009 & & 0.018 & \\
\hline ITSA044 & 9.643 & 45.124 & 0.014 & & & \\
\hline ITSA045 & 9.919 & 44.815 & 0.014 & 0.005 & & \\
\hline ITSA046 & 10.520 & 44.561 & 0.014 & 0.001 & & \\
\hline ITSA047 & 11.424 & 44.425 & 0.014 & 0.001 & & \\
\hline ITSA048 & 10.777 & 45.771 & 0.022 & & & \\
\hline ITSA049 & 10.727 & 44.810 & 0.015 & & & \\
\hline ITSA050 & 11.508 & 44.869 & 0.014 & 0.001 & & \\
\hline ITSA051 & 11.212 & 44.794 & 0.014 & 0.001 & 0.010 & 0.001 \\
\hline ITSA052 & 14.780 & 42.946 & 0.010 & & & \\
\hline ITSA053 & 16.099 & 38.479 & 0.131 & 0.044 & 0.116 & 0.022 \\
\hline ITSA054 & 13.898 & 43.016 & 0.008 & & 0.012 & \\
\hline ITSA055 & 15.918 & 38.228 & 0.140 & & 0.027 & \\
\hline ITSA056 & 12.493 & 43.279 & 0.041 & & 0.026 & \\
\hline
\end{tabular}




\begin{tabular}{|c|c|c|c|c|c|c|c|}
\hline \multirow[t]{15}{*}{ Table 6 (continued) } & SA ID & Lon. E & Lat. $\mathrm{N}$ & $\mathrm{P} 1-6.0$ & $\mathrm{P} 1-6.5$ & P2-6.0 & $\mathrm{P} 2-6.5$ \\
\hline & ITSA057 & 15.040 & 41.243 & 0.064 & 0.064 & 0.001 & 0.001 \\
\hline & ITSA058 & 15.837 & 41.717 & 0.149 & & 0.003 & \\
\hline & ITSA059 & 14.750 & 42.179 & 0.137 & & 0.010 & \\
\hline & ITSA060 & 12.330 & 45.982 & 0.046 & 0.005 & & \\
\hline & ITSA061 & 13.240 & 46.262 & 0.036 & & & \\
\hline & ITSA062 & 12.836 & 46.205 & 0.004 & 0.004 & & \\
\hline & ITSA063 & 15.494 & 40.873 & 0.037 & 0.015 & 0.073 & 0.010 \\
\hline & ITSA064 & 13.082 & 46.306 & 0.021 & & & \\
\hline & ITSA065 & 13.391 & 45.969 & 0.023 & & & \\
\hline & ITSA066 & 13.255 & 46.215 & 0.032 & 0.004 & & \\
\hline & ITSA067 & 13.042 & 46.477 & 0.013 & & & \\
\hline & ITSA068 & 16.357 & 38.817 & 0.047 & 0.007 & 0.044 & 0.003 \\
\hline & ITSA070 & 16.579 & 41.635 & 0.036 & 0.028 & & \\
\hline & ITSA071 & 12.806 & 46.218 & 0.004 & 0.004 & & \\
\hline \multirow{4}{*}{$\begin{array}{l}\text { P1 indicates the results } \\
\text { obtained with geodetic } \\
\text { constraints, P2 those with } \\
\text { geophysical constraints. }\end{array}$} & ITSA075 & 13.925 & 42.492 & 0.009 & & 0.010 & \\
\hline & ITSA077 & 14.510 & 41.660 & 0.030 & 0.030 & 0.001 & 0.001 \\
\hline & ITSA079 & 14.613 & 41.989 & 0.042 & 0.012 & 0.022 & 0.002 \\
\hline & ITSA080 & 16.164 & 38.434 & 0.141 & & 0.012 & \\
\hline \multirow{8}{*}{$\begin{array}{l}\text { The name of the } \\
\text { seismogenic areas } \\
\text { (SA ID) is made up of } \\
\text { the country code (CH for } \\
\text { Switzerland, FR for } \\
\text { France, IT for Italy, SI for } \\
\text { Slovenia) followed by SA, } \\
\text { and the code number of } \\
\text { the seismogenic area }\end{array}$} & ITSA084 & 15.302 & 41.041 & 0.052 & 0.052 & 0.003 & 0.003 \\
\hline & ITSA087 & 15.356 & 40.855 & 0.048 & & 0.044 & \\
\hline & ITSA089 & 15.881 & 40.969 & 0.095 & 0.002 & 0.004 & \\
\hline & SISA001 & 13.838 & 46.201 & 0.008 & & & \\
\hline & SISA002 & 13.945 & 46.055 & 0.024 & 0.014 & & \\
\hline & SISA003 & 13.525 & 46.291 & 0.003 & & & \\
\hline & SISA004 & 14.074 & 45.705 & 0.008 & & & \\
\hline & SISA005 & 13.628 & 46.019 & 0.009 & & & \\
\hline
\end{tabular}

areas along the northern coast of Sicily according to the geodetic constraint: the eastern one shows a higher probability for $M_{\mathrm{W}} \geq 6.0$ (Fig. 6a), while the western one does for $M_{\mathrm{W}} \geq 6.5$ (Fig. 7a). This aspect simply shows that events with an $M_{\mathrm{W}} \geq 6.5$ are more likely to occur along the western sector, while events with an $M_{\mathrm{W}}$ between 6 and 6.5 are largely more probable along the eastern one.

The 30-year probability for $M_{\mathrm{W}} \geq 6.0$ based on our geodetic modelling approach (Fig. 6a) is low everywhere and varies in one seismogenic area to another mainly from $1 \%$ to $5 \%$. Most of the most 'hazardous' seismogenic areas (in terms of earthquake probabilities) are located in the southern Apennines (black large dots in Fig. 6a, corresponding to a probability greater than $5 \%$ ). The equivalent probabilities in the case of the results obtained from the geophysical modelling approach (Fig. 6b) are very similar to those with geodetic constraints (Fig. 6a) showing almost the same seismogenic areas. Some disagreements can be noted along the Adriatic coast, where the forecasts from the geophysical modelling are higher than those from the geodetic model in the central sector and lower in the southern one. In the southern sector, the geophysical model has been mainly constrained through Serpelloni et al. (2007) geodetic data, showing a moment rate that is lower than the moment rate relative to the geodetic data used to derive the earthquake rates within this work. We consider the probabilities derived by the current geodetic data more reliable than those derived by the geophysical model in the southeastern side of the peninsula as the current data are greater in number and more accurate. The largest probabilities for $M_{\mathrm{W}} \geq 6.0$ are found in the southern Apennines, where they reach values between $10 \%$ and $20 \%$ (Fig. $6 \mathrm{~b}$ ).

The 30-year probability for $M_{\mathrm{W}} \geq 6.5$ (Fig. 7) is obviously very low again and varies mainly between $0.4 \%$ and $3 \%$. The agreement between the estimates according the two approaches is again fairly good, although the estimates under 


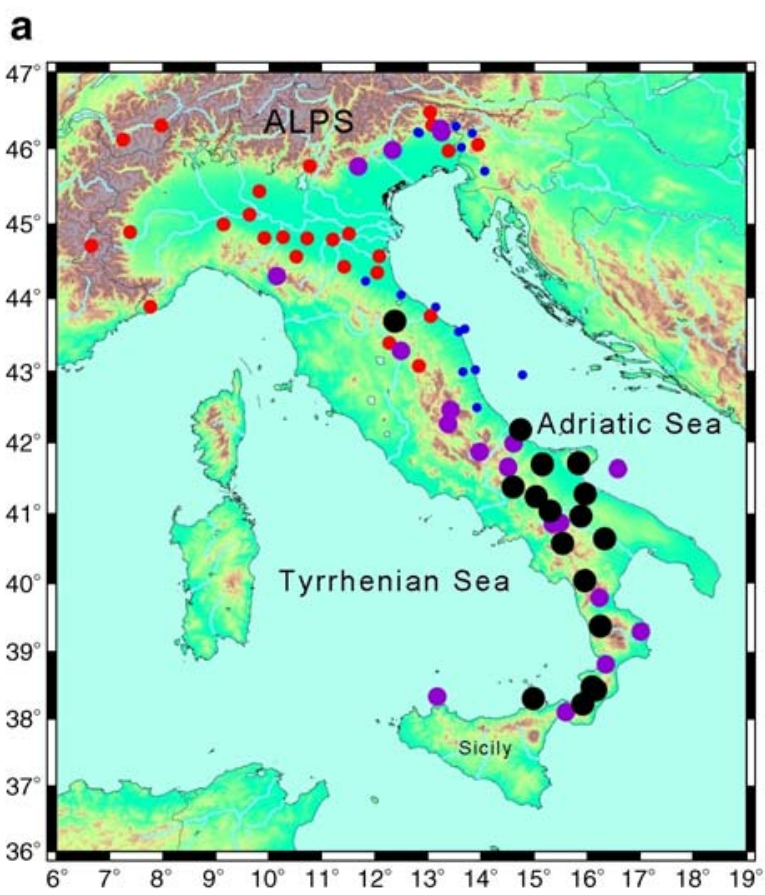

Fig. 6 Thirty-year probability for $M_{\mathrm{W}} \geq 6.0$ according to a Poisson model: a computed by geodetic constraints, b computed by geophysical constraints. Blue small dots for

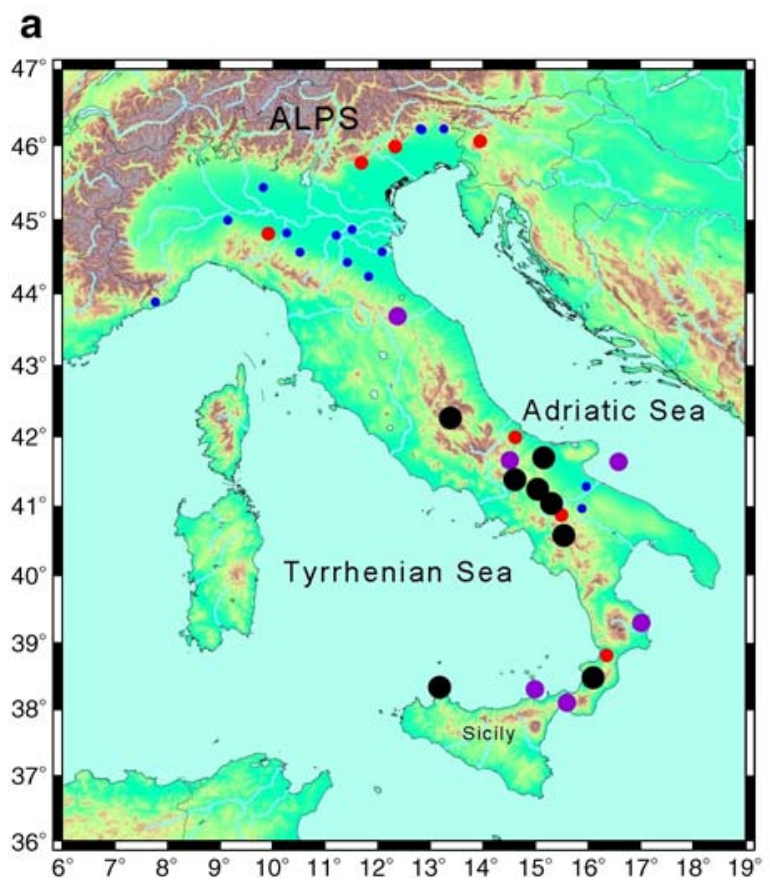

Fig. 7 Thirty-year probability for $M_{\mathrm{W}} \geq 6.5$ according to a Poisson model: a computed by geodetic constraints, b computed by geophysical constraints. Blue small dots for b

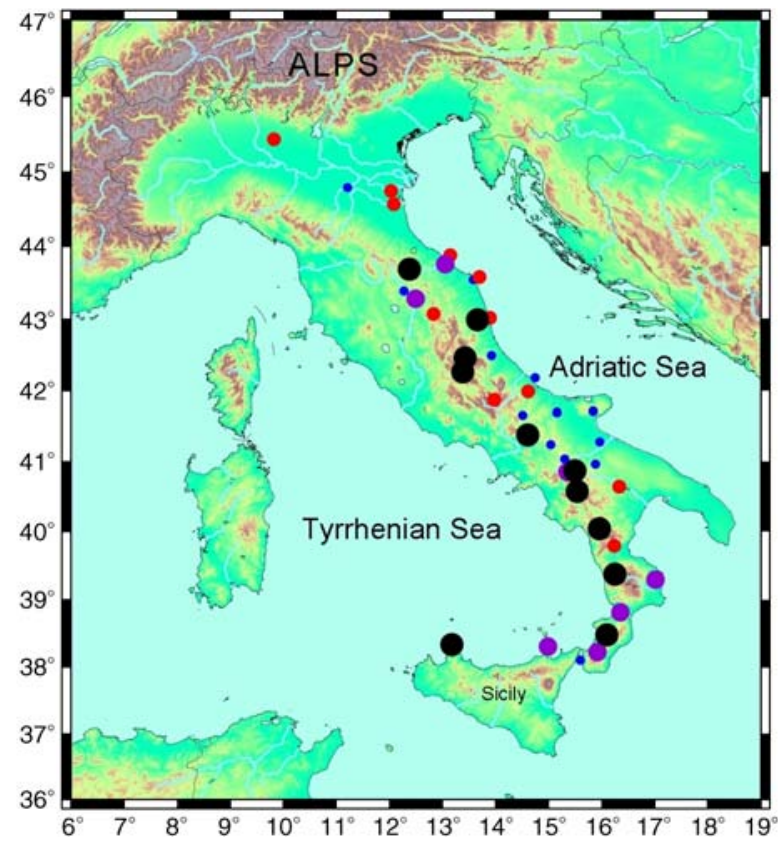

$P \leq 1 \%$; red medium dots $1 \%<P \leq 2.5 \%$; purple medium circles $2.5 \%<P \leq 5 \%$, black large circles $P>5 \%$

b

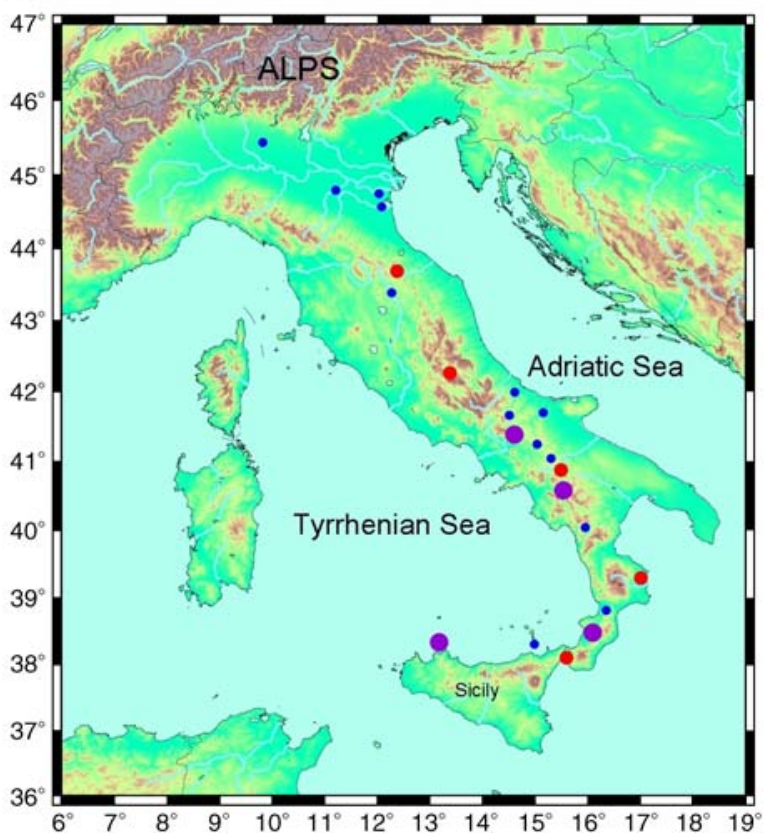

$P \leq 0.4 \%$; red medium dots $0.4 \%<P \leq 1.5 \%$; purple medium circles $1.5 \%<P \leq 3 \%$, black large circles $P>3 \%$ 
geophysical constraints are slightly lower. Again a disagreement can be noted in a small sector of the southern Apennines. The largest probabilities are found again in the southern Apennines, where they reach values lower than $10 \%$.

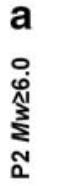

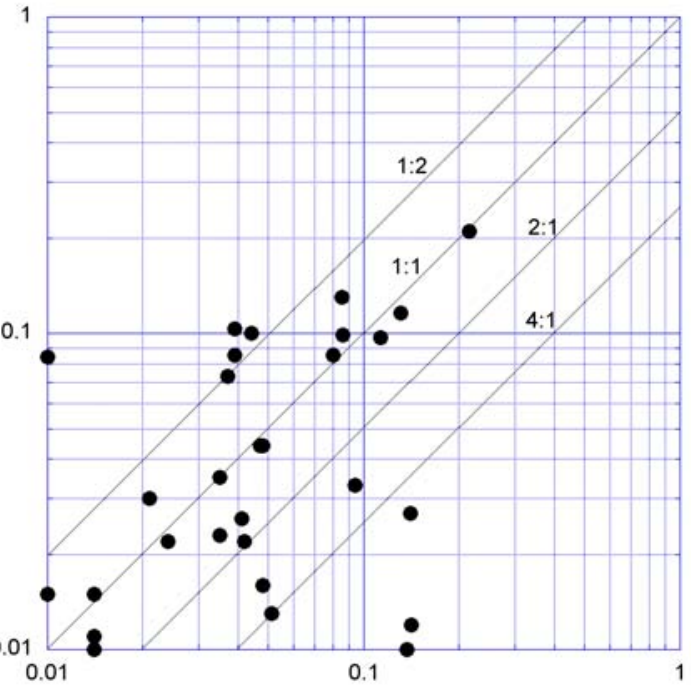

P1 $M w \geq 6.0$

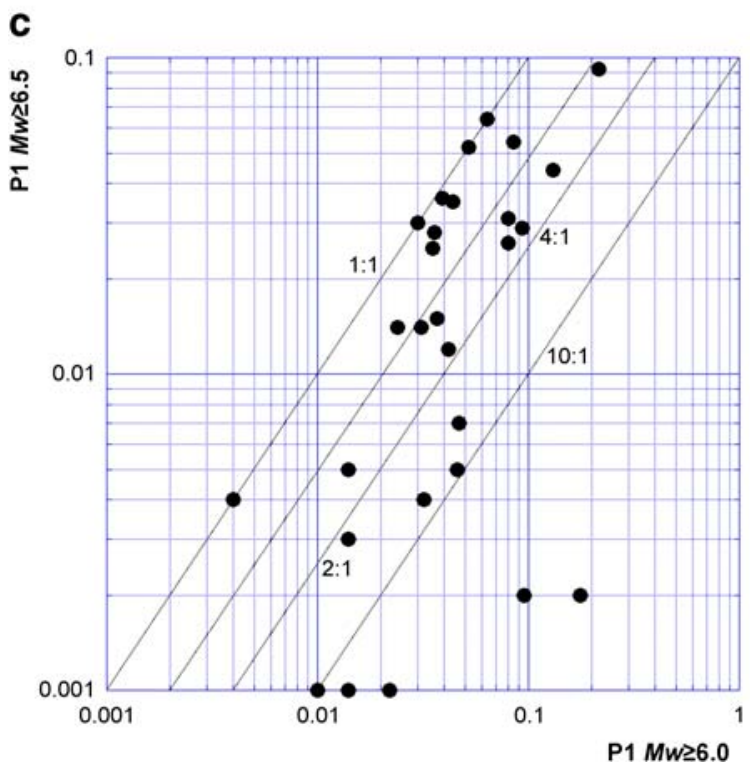

Fig. 8 Comparison of the probability estimates ( $P 1$ indicates the exceedance probability in 30 years computed with geodetic constraints, $P 2$ indicates the exceedance probability in 30 years computed with geophysical constraints):
Figure 8 shows the differences between the estimates obtained by considering the two different constraints and quantifies how much the results with the geodetic constraints differ from those from geophysical modelling. Considering $M_{\mathrm{W}} \geq$

b

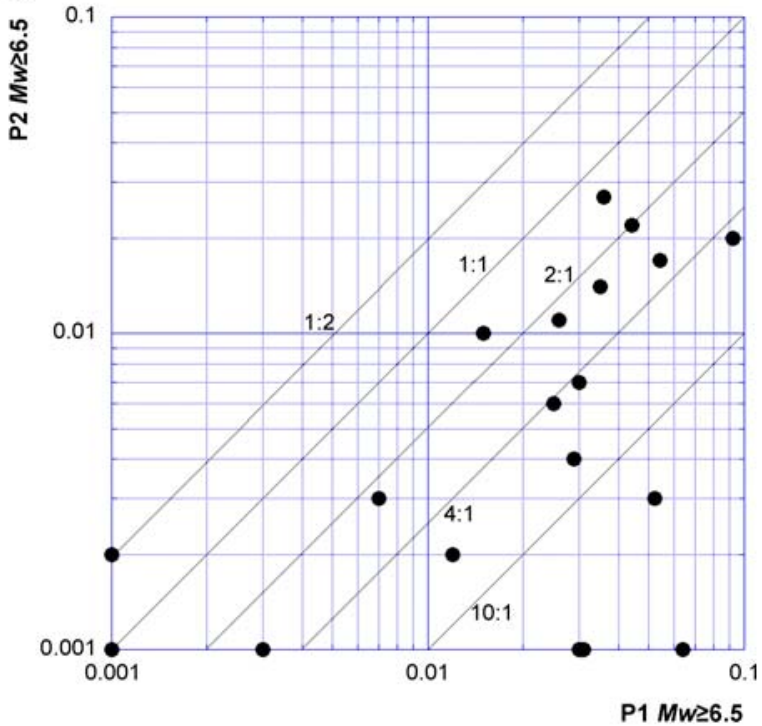

d

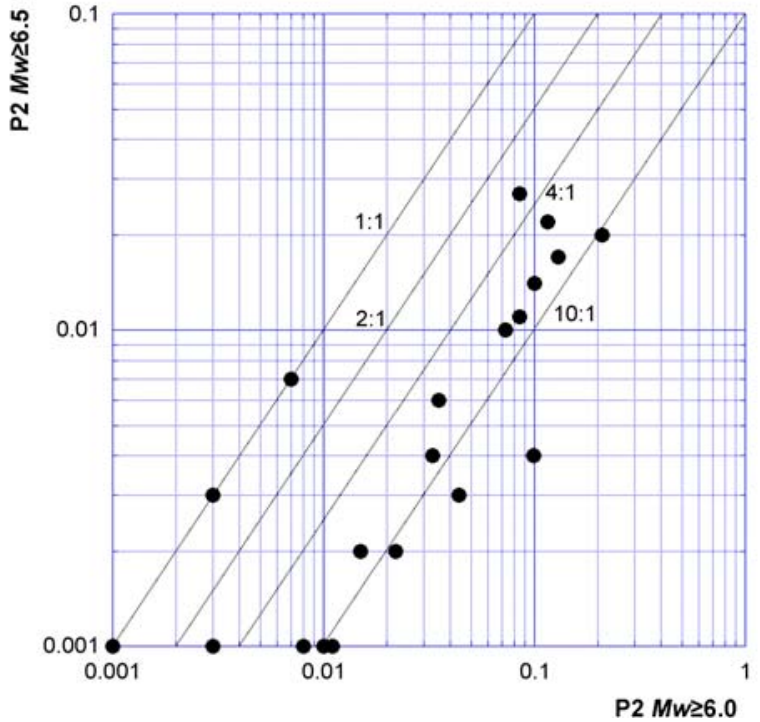

a $\mathrm{P} 2$ vs. $\mathrm{P} 1$ for $M_{\mathrm{W}} 6.0$, b $\mathrm{P} 2$ vs. $\mathrm{P} 1$ for $M_{\mathrm{W}} 6.5$, c $\mathrm{P} 1$ for $M_{\mathrm{W}} 6.5$ vs. $\mathrm{P} 1$ for $M_{\mathrm{W}} 6.0$, d $\mathrm{P} 2$ for $M_{\mathrm{W}} 6.5$ vs. $\mathrm{P} 2$ for $M_{\mathrm{W}}$ 6.0 
6.0 (Fig. 8a), it can be seen that the great majority of points remain within the lines indicating the ratios $1: 2$ and 2:1, that is where the results with one approach are less than double those with the other approach. There are a few among the remaining points where the estimates with geodetic constraints are by far larger (more than four times) than those taken from geophysical modelling. The situation is worse when events with an $M_{\mathrm{W}} \geq 6.5$ are considered (Fig. 8b). In this case, almost all forecasts with geodetic constraints are larger than those from geophysical modelling and even values 10 times and larger are obtained in a few cases.

The only region where the estimates with the two approaches, referring to $M_{\mathrm{W}} \geq 6.0$ and $M_{\mathrm{W}} \geq$ 6.5 as well, differ greatly is the promontory in the southern Adriatic sea (Gargano promontory). There, the forecasts from the geophysical modelling are much lower than those with geodetic constraints: this difference is notably larger than that in the rest of Italy.

Some explanations for the differences shown by the two approaches can be suggested. Both methods suffer some limitations: the geodetic one because it was possible to compute the strain rate over wide regions (the four domains, see Appendix A) and some peculiar differences are, consequently, lost. The geophysical modelling is not yet perfectly tuned and a satisfactory agreement with all the boundary conditions is not reached yet (see Appendix B).

The lack of proportionality between the estimates referring to a different magnitude threshold has been already justified, and is more evident in the case of a geodetic constraint (Fig. 8c) than when data from the geophysical modelling have been used (Fig. 8d). The latter, in fact, display quite a nice alignment along the line 10:1, indicating that the probability of $M_{\mathrm{W}} \geq 6.0$ is about 10 times larger than that of $M_{\mathrm{W}} \geq 6.5$.

\section{Conclusions}

We have developed two new approaches to estimating earthquake probabilities for moderateto-large earthquakes in Italy, using geodetic and geophysical modelling methods. The two ap- proaches show a good agreement in the resulting probabilities, with noticeable differences only in limited areas of Italy. Thirty-year probabilities both based on geodetic and geophysical constraints are less than $5 \%$ for $M_{\mathrm{W}} \geq 6.0$ with the exception of the southern Apennines, where they reach values between $10 \%$ and $20 \%$ in a very few seismogenic areas. In the same areas, 30year probabilities for $M_{\mathrm{W}} \geq 6.5$ remain lower than $10 \%$. Future work will be focused on improving the methodologies developed, in an effort to constrain better the derived earthquake probabilities.

Acknowledgements The present study has been developed in the framework of the projects of interest for the Italian Department of Civil Protection and financed by the National Institute of Geophysics and Volcanology. Many thanks are due to Roberto Basili, INGV Rome, who helped us with his great expertise in the data treatment of the Database of the Italian Seismogenic Sources, and Laura Peruzza, OGS Trieste, and Steven Ward, University of California at Santa Cruz, for valuable discussions. We wish to express our deep gratitude to David Perkins, USGS Denver, and to an anonymous reviewer, both have greatly improved this paper with their valuable suggestions and remarks. Most of the figures were produced using the Generic Mapping Tool (GMT) software package (Wessel and Smith 1991).

\section{Appendix A: Geodesy}

\section{A1 Validation of GPS velocity data}

The analysis of GPS data normally rests on the IGS standards: these prescribe consistent orbits and Earth Rotation Parameters, and recommend models for Phase Center Variations of the antennas, the elevation cutoff angle and a set of datum defining coordinates and velocities. The final product of the adjustment must be available in the SINEX format and the constraints adopted in the adjustment must be explicitly given, so that further analyses can be made with possibly different constraints.

An example of this procedure is given by the weekly maintenance of the European Reference Frame done by the European Permanent Network (http://www.epncb.oma.be): 16 local analysis centers (LACs) process partially overlapping sub-networks of several tens of permanent GPS stations in Europe. The 16 weekly solutions in 
SINEX format and with removable constraints are combined into one network solution by an independent combination center. The constraints imposed by the individual analysis centers are removed and new constraints are imposed, so that the final adjustment is properly aligned with the IGS reference frame. The comparison of the individual sub-network solutions with the final network solutions yields a quantitative estimate of the mutual consistency of the processing strategies of the LACs. Typical discrepancies between solutions are at the sub millimeter level in translation, fraction of milliarcsec in rotation and few parts per billion in scale. Furthermore, local analysis centers process regional networks, e.g. at a national level, of permanent GPS stations using the same standards as for the EPN sub-networks. This results in additional SINEX files, which may be combined with the EPN SINEX files at corresponding epochs for network densification. Several software packages are available for such combination work: Bernese's ADDNEQ or ADDNEQ2, CATREF, GIPSY, GLOBK are well-known examples. The SINEX format has the advantage that is a software independent format. Hence SINEX files, if generated by a standardized processing, can be considered a form of metadata of higher level than the RINEX files containing raw phase and pseudorange data.

The rest of this appendix analyses velocities and derived products (velocity field, strain rate) of permanent GPS stations resulting from a combination of the weekly SINEX files concerning the EPN, an Italian network processed by the University of Padua (UPA) and an Austrian network processed by the Astronomical Observatory in Graz (GP_). Both Padova and Graz are EPN Local Analysis Centers.

The SINEX used in the combination analysis are summarized as follows:

- European network (EUR $<$ GPSwk $>$.SNX) from GPS week 860 to 1380 ( 1996 to 2006);

- Italian Network (UPA $<$ GPSwk $>$.SNX) from GPS week 995 to 1380 ( 1999 to 2006);

- Austrian Network (GP_<GPSwk $>$.SNX) from GPS week 995 to 1380 ( 1999 to 2006).

Beginning GPS week 995, the three normal equations are combined with the program
ADDNEQ of the Bernese Software v.4.2 and the appropriate constraints are imposed on those stations with position and velocities listed in the ITRF2000 solution. Because our combination scheme fully considers the variance covariance matrix of the individual network solutions, also the non-ITRF2000 stations have coordinates consistently defined with that system. To ensure that the EPN solution is the backbone, the weight of its SINEX files is larger than for the UPA and GP solutions

A total of 372 permanent GPS stations are present in the combined network, although only for a fraction of them a reliable estimate of the velocity can be made. The ITRF2000 (Altamimi et al. 2002) constraints in position and velocity of the datum defining stations are available at http:// itrf.ensg.ign.fr/ITRF_solutions/2000/sol.php. The datum defining stations are listed below, and are chosen on the basis of their continuous tracking for several years. Figure 9 shows the velocities of stations with sufficiently reliable time series (2.5 years minimum), which were used in the subsequent strain rate analysis.

\section{A2 Statistical properties of the estimated velocities}

The horizontal velocities estimated in the ITRF2000 frame exhibit a dominant NE trend of the order of $2 \mathrm{~cm} /$ year. Most of this signal can be accounted for with a rigid rotation about an Eulerian pole and can be filtered out. The residual velocities (Fig. 9) are spatially correlated: the likelihood that two stations have similar velocities decreases with increasing distance between the two stations. This likelihood function is shown in Fig. 10 and forms the basis for computing a velocity field and strain rates out of the observed velocities. According to the analytical model shown in Fig. 10, the characteristic distance $d_{0}$ is such that the likelihood of velocities of sites at such distance is reduced to $50 \%$ that at zero lag. More details are given in Caporali et al. (2003).

Once the velocities and their uncertainties are given at each GPS station, and the correlation function has been specified, the velocities and their uncertainties can be interpolated at other 
Fig. 9 Horizontal velocities of GPS permanent stations in the Alpine Mediterranean area, after removing a common rigid rotation which approximates the rigid rotation of the Eurasian plate in the ITRF2000 frame. Error ellipses are $2 \sigma$. Velocities have been computed only for stations with at least 2.5 years of continuous tracking. Not shown are the velocities of EPN stations falling outside the plotting box

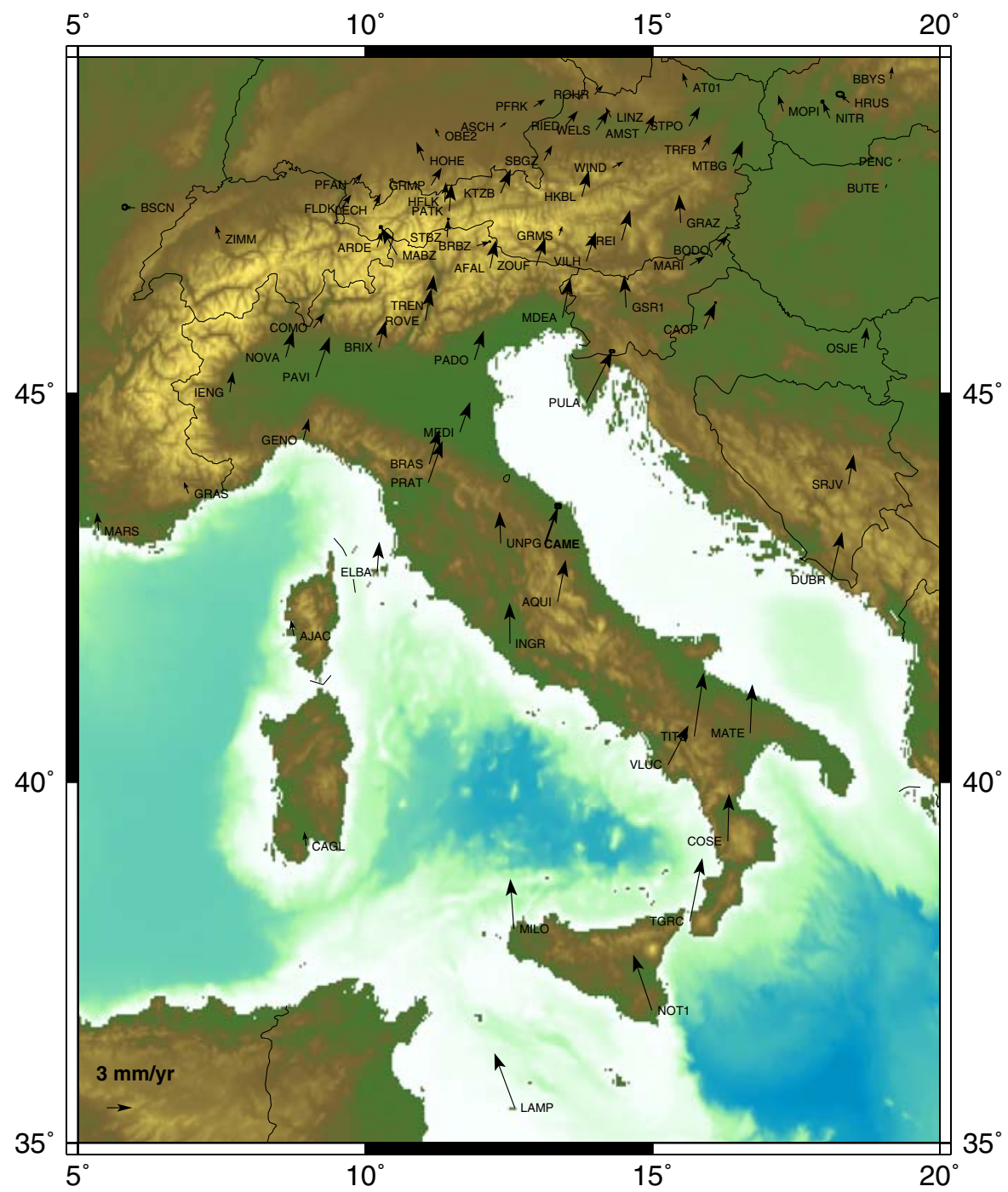

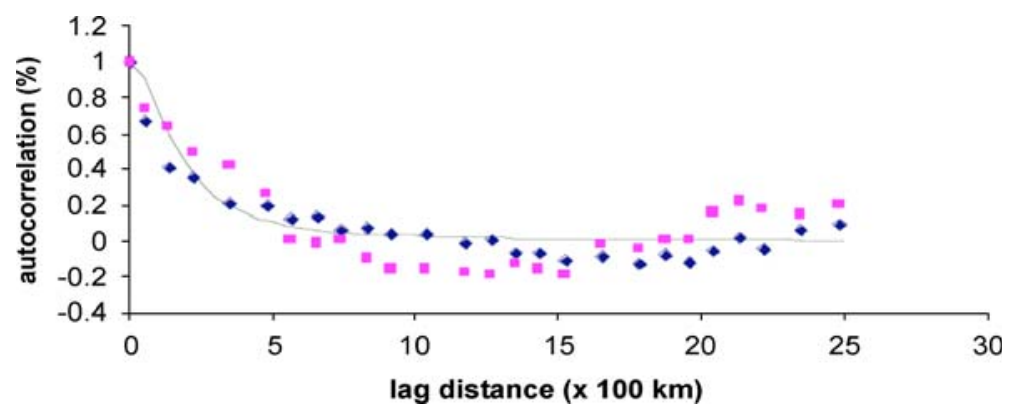

Fig. 10 The autocorrelation of the observed velocities as a function of the distance between stations. The continuous curve represents an analytical covariance function depend- ing on the inverse squared distance. The fit to the observed autocorrelation defines a scale distance in the range 150 to $250 \mathrm{~km}$. The cross-correlation is negligibly small 
points $\mathrm{P}$ by a minimum variance (or 'optimal') algorithm known as least squares collocation:

$$
\begin{aligned}
{\left[\begin{array}{l}
v_{n} \\
v_{e}
\end{array}\right]_{P} } & =\sum_{s} C\left(d_{P, s}\right) \sum_{s^{\prime}}\left[C\left(d_{s, s^{\prime}}\right)+W_{s s^{\prime}}\right]^{-1} \cdot\left[\begin{array}{l}
v_{n} \\
v_{e}
\end{array}\right]_{s^{\prime}} \\
s, s^{\prime} & =\text { station indices }
\end{aligned}
$$

with

$$
W_{s s^{\prime}}=\frac{\frac{1}{\sigma_{s}^{2}}}{\sum_{s^{\prime \prime}} \frac{1}{\sigma_{s^{\prime \prime}}^{2}}} \delta_{s s^{\prime}}
$$

The mean velocity is removed prior to interpolation and added back to the interpolated value.

Likewise, the velocity derivatives [Eq. 14] yield a velocity gradient, or strain rate tensor:

$$
\begin{aligned}
{\left[\begin{array}{ll}
v_{n, n} & v_{n, e} \\
v_{e, n} & v_{e, e}
\end{array}\right]_{P}=} & \sum_{s}\left[\begin{array}{ll}
\frac{\partial C}{\partial n} & \frac{\partial C}{\partial e} \\
\frac{\partial C}{\partial n} & \frac{\partial C}{\partial e}
\end{array}\right]_{P, s} \\
& \times \sum_{s^{\prime}}\left[C\left(d_{s, s^{\prime}}\right)+W_{s s^{\prime}}\right]^{-1} \cdot\left[\begin{array}{c}
v_{n} \\
v_{e}
\end{array}\right]_{s^{\prime}} \\
s, s^{\prime}= & \text { station indices }
\end{aligned}
$$

The fact that the individual velocities have different uncertainties is embodied into the algorithm by augmenting the correlation matrix $C$ between the sites with a weight matrix $W$ built with the variances of the individual velocities. This set up ensures that the resulting velocity field will be smooth. The velocity field, when computed at the location of a GPS station, will be closer to the observed velocities, the smaller the associated uncertainty. In general the weight matrix $W$ acts as a smoother or low pass filter. This ensures that local velocity anomalies, e.g. induced by monument instabilities, will not affect the velocity field or the strain rate.

The components of the strain rate matrix [Eq. 14] are expressed in a geographical frame. The eigenvectors and their azimuth can be computed by standard matrix diagonalization. We consider as extensional the eigenvector with positive eigenvalue.
The estimate of the strain rate involves a differentiation and must be done with great care. While the interpolation of the velocity reduces the noise by smoothing (integration), differentiation tends to amplify the noise, especially over short distances. If two stations separated by a distance $d$ have each an uncorrelated uncertainty $s$ in the velocity, then a quick estimate of the uncertainty in the resulting strain rate is $2^{1 / 2} s / d$. If $s=0.5 \mathrm{~mm} /$ year and $d=100 \mathrm{~km}$, the expected uncertainty is 7 nstrain/year $\left(1\right.$ nstrain $\left.=10^{-9}\right)$. Shorter distances will proportionally increase the uncertainty to levels above the sought for signal, which is of the order of several tens up to 100 of nstrain/year, typically.

It is crucial to identify the optimal locations, from the point of view of minimal variance, where the strain rate can be reliably computed. A first criterion for optimal choice is that there exist uniformly distributed stations in the neighborhood of the computation point. A second criterion is that the nearest stations should be given higher weight than more distant stations, if their velocities have the same variance. This last criterion is automatically satisfied by the collocation algorithm. To ensure that the strain rate is computed at points such that it is sufficiently well constrained by data from neighboring stations we have adopted the following rule: the strain rate is computed at the geographical location of those permanent stations of known velocity, such that at least one additional station with known velocity exists in each quadrant within a radius equal to the correlation distance $d_{0}$.

The adopted rule is exemplified in Fig. 11. We require that within a circle of radius $d_{0}$ five velocities are defined: the velocity at the center of the circle and at four additional sites. The least squares collocation represents in a continuous form a finite difference between the center velocity and the peripheral velocities. In this manner we ensure that the resulting strain rate reliably describes the rate of deformation in the circled area. Unfortunately the strain rate computed by this rather conservative approach not always relates to areas of seismological interest. Mapping the strain rate to other locations is mathematically feasible but not recommended, due to the fast increase of the variance. 


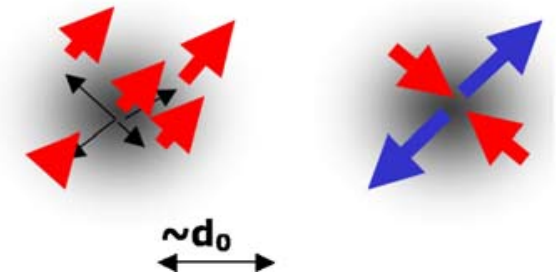

Fig. 11 Example of strain rate calculation. On the left figure five sites are present: one is at the center of a circle of radius equal to the typical correlation length of the ensemble of velocities, and four additional velocities are uniformly distributed about that point within the circle. On the right we have the corresponding strain rate eigenvectors. The structure of the velocity distribution is such that one expects an extension in the NE-SW direction. This deformation regime is then a mean property of the entire circular area

\section{A3 Numerical results}

The numerical results for northern, central, and southern Italy obtained with the velocities of permanent GPS stations resulting from the combined analysis described above were used as geodetic constraints in the computation of the earthquake occurrence probabilities (Table 2). For southern Italy we have a number of stations insufficient to meet the adopted criterion for strain rate computation. Therefore we have used a set of velocities coming from campaign and permanent stations, available from the literature and processed by analysis centers outside the EUREF network. For this reason we have thought it appropriate not mixing the sets of velocities, although the methodologies of computation are, in a broad sense, consistent with each other.

\section{Appendix B: Finite-element modelling}

The finite-element modelling aimed to reproduce a large amount of neotectonic data for Italy by means of trial-and-error approach, using thin-shell finite element code SHELLS (Bird 1999), in a large number of iterations which mostly differ by boundary conditions, fault friction coefficient [as for example in Barba (2007) and Barba et al. $(2008,2009)]$. In all these studies, model predictions were compared to three independent data sets: geodetic horizontal velocities from tem- porary and permanent GPS stations (Serpelloni et al. 2007; Caporali 2007); stress regime data, based on relative stress magnitudes, and the directions of maximum horizontal compressive stress (Montone et al. 2004). Residuals between model predictions and the calibration data sets allowed to characterize of the degree of realism of the numerical results. The model results that exhibited the lowest misfits were averaged, thereby accounting for uncertainties in boundary conditions and model parameters. Misfits were standardized to account for the different calibration datasets.

The model incorporates faults and realistic rheology in a two-layer grid (crust and lithospheric mantle) with laterally varying seismogenic thickness, heat flow, and topography. The horizontal components of the momentum equation (Kong and Bird 1995) were solved to predict long-term horizontal velocities, anelastic strain rates, vertically integrated stresses, and fault slip rates.

In the thin-shell neotectonic modelling program SHELLS [Bird (1999) and references therein] uses isostasy and vertical integration of lithospheric strength to reduce the threedimensional problem of deforming lithosphere to two dimensions, where the horizontal velocity components do not depend on the depth. The components of the momentum equation are vertically integrated using 1-km steps at each of seven Gauss integration points in each finite element (continuum or fault) and the horizontal components of velocity predicted. The vertical component of the momentum equation comes from the assumption of isostatic equilibrium (Bird 1989). The model is composed of two layers with variable thicknesses, plus the topography. Temperature, strength, and the shear stress tensor are depth dependent. By integrating the shear stress along $z$ the problem is reduced to the plane strain. By computing the corresponding strain solution using only the in-plane terms makes the problem bidimensional. SHELLS solves the momentum equation in two dimensions, and the normal vertical stress, assumed as lithostatic, is then added to the result.

The rheology has the same analytical form at all points of the model. The code neglects all elastic strain accumulation and release and solves for velocities, fault slip rates, and anelastic 
strain rates and stresses. Deformation occurs by frictional sliding or nonlinear dislocation creep. Given a strain rate, the deviatoric stress is evaluated separately for each of three flow laws: frictional faulting, dislocation creep (power law), and Newtonian creep (linear). At each point, the flow law that provides the lowest maximum shear stress is selected. The rheological parameters are different for the crust and mantle lithosphere. The rheological parameters impose the lithospheric rigidity and the coupling between the crust and the lithospheric mantle. The chosen parameters represent an average lithosphere. Frictional faulting stress is evaluated under the assumption of hydrostatic pore pressure. Faults are distinguished from continuum elements because of double "slipping" nodes, and a lower frictional coefficient with respect to the continuum medium.

The method incorporates some 3-D characteristics since volume integrals of density and strength are performed numerically in a lithosphere model with laterally varying crust and mantle-lithosphere layer thicknesses, heat flow, and elevation. Crustal and lithospheric mantle structure, and steady state thermal regime have been derived from literature data.

\section{References}

2007 WGCEP (Working Group on California Earthquake Probabilities) (2008) The uniform California earthquake rupture forecast, version 2 (UCERF 2). USGS Open File Report 2007-1437, U.S. Geological Survey, Reston, Virginia, $104 \mathrm{pp}$

Albarello D, Mucciarelli M (2002) Seismic hazard estimates using ill-defined macroseismic data at site. Pure Appl Geophys 159:1289-1304

Altamimi Z, Sillard P, Boucher C (2002) ITRF2000: a new release of the International Terrestrial Reference Frame for earth science applications. J Geophys Res 107(B10):2214. doi:10.1029/2001JB000561

Barba S (2007) Numerical modelling of strain rates in Italy. IUGG Perugia, Abstract 11886

Barba S, Carafa MMC, Boschi E (2008) Experimental evidence for mantle drag in the Mediterranean. Geophys Res Lett 35: doi:10.1029/2008GL033281

Barba S, Carafa MMC, Mariucci MT, Montone P, Pierdominici S (2009) Active stress field modelling in the southern Apennines (Italy) using new borehole data. Submitted to Tectonophysics

Basili R, Valensise G, Vannoli P, Burrato P, Fracassi U, Mariano S, Tiberti MM (2008) The database of individual seismogenic sources (DISS), version 3: sum- marizing 20 years of research on Italy's earthquake geology. Tectonophysics 453:20-43 doi:10.1016/j.tecto. 2007.04.014

Bird P (1989) New finite element techniques for modeling deformation histories of continents with stratified temperature-dependent rheology. J Geophys Res 94:3967-3990

Bird P (1999) Thin-plate and thin-shell finite-element programs for forward dynamic modeling of plate deformation and faulting. Comput Geosci 25(3):383-394

Bressan, Bragato (2009) Seismic deformation pattern in the Friuli-Venezia Giulia region (north-eastern Italy) and western Slovenia. Boll Geof Teor Appl 50:255275

Caporali A (2007) Geophysical characterization of the main seismogenic structures. In Final Reports of the Project "Assessing the Seismogenic Potential and the Probability of Strong Earthquakes in Italy," edited by D. Slejko and G. Valensise, pp. 25-42, Ist. Naz. di Geofis. e Vulcanol., Rome (available at http://hdl.handle.net/2122/3090)

Caporali A, Martin S, Massironi M (2003) Average strain rate in the Italian crust inferred from a permanent GPS network. Part 2: strain rate vs. seismicity and structural geology. Geophys J Int 155:254-268

Caporali A, Aichhorn C, Becker M, Fejes I, Gerhatova L, Ghitau L, Grenerczy Gy, Hefty J, Krauss S, Medak D, Milev G, Mojzes M, Mulic M, Nardo A, Pesec P, Rus T, Simek J, Sledzinski J, Solaric M, Stangl G, Vespe F, Virag G, Vodopivec F, Zablotskyi F (2008) Geokinematics of Central Europe: new insights from the CERGOP-2/Environment Project, J. of Geodynamics (accepted manuscript)

Frankel A, Mueller C, Harmsen S, Wesson R, Leyendecker E, Klein F, Barnhard T, Perkins D, Dickman N, Hanson S, Hopper M (2000) USGS National Seismic Hazard Maps. Earthq Spectra 16:1-20

Gruppo di lavoro CPTI (2004) Catalogo Parametrico dei Terremoti Italiani, versione 2004 (CPTI04). INGV, Bologna. http://emidius.mi.ingv.it/CPTI04/

Hanks TC, Kanamori H (1979) A moment magnitude scale. J Geoph Res 84:2348-2350

Kong X, Bird P (1995) Shells: a thin-plate program for modeling neotectonics of regional or global lithosphere with faults. J Geophys Res 100:22129-22131

Kostrov VV (1974) Seismic moment and energy of earthquakes, and seismic flow of rock. Izv Earth Physics English Transl 1:13-21

Montone P, Mariucci MT, Pondrelli S, Amato A (2004) An improved stress map for Italy and surrounding regions (central Mediterranean). J Geophys Res 109:B10410 doi:10.1029/2003JB002703

Peruzza L (2006) Earthquake probabilities and probabilistic shaking in Italy in 50 years since 2003: trials and ideas for the 3rd generation of Italian seismic hazard maps. Boll Geof Teor Appl 47:515-548

Peruzza L, Pace B, Cavallini F (2009) Error propagation in time-dependent probability of occurrence for characteristic earthquakes in Italy. J Seismol

Press WH, Teukolsky SA, Vetterling WT, Flannery BP (1992) Numerical recipes in Fortran-the art of scien- 
tific computing, 2nd edn. Cambridge University Press, Cambridge, 963 pp

Savage JC, Simpson RW (1997) Surface strain accumulation and seismic moment tensor. Bull Seism Soc Am $87: 1345-1353$

Schwartz DP, Coppersmith KJ (1984) Fault behavior and characteristic earthquakes: examples from the Wasatch and San Andreas fault zones. J Geophys Res 89:5681-5698

Serpelloni E, Anzidei M, Baldi P, Casula G, Galvani A, Pesci A, Riguzzi F (2002) Combination of permanent and non permanent GPS networks for the evaluation of the strain rate field in the Central Mediterranean area. Boll Geofis Teor Appl 43(3/4):195-219

Serpelloni E, Vannucci G, Pondrelli S, Argnani A, Casula G, Anzidei M, Baldi P, Gasperini P (2007) Kinematics of the Western Africa-Eurasia plate boundary from focal mechanisms and GPS data. Geophys J Int 169(2):1180-1200

Stirling MW, Wesnousky SG, Berryman KR (1998) Probabilistic seismic hazard analysis of New Zealand. N Z J Geol Geophys 41:355-375

Stirling MW, Peruzza L, Slejko D, Pace B (2007) Seismotectonic modelling in northeastern Italy. GNS Science Consultancy Report 2007/84, GNS Science, Wellington, $22 \mathrm{pp}$
Ward SN (1994) A multidisciplinary approach to seismic hazard in southern California. Bull Seism Soc Am 84:1293-1309

Ward SN (1998) On the consistency of earthquake moment rates, geological fault data, and space geodetic strain: the United States. Geoph J Int 134:172-186

Ward SN (2007) Methods for evaluating earthquake potential and likelihood in and around California. Seismol Res Lett 78:121-133

Weichert (1980) Estimation of the earthquake recurrence parameters for unequal observation periods for different magnitudes. Bull Seism Soc Am 70:1337-1346

Wells DL, Coppersmith KJ (1994) New empirical relationship among magnitude, rupture length, rupture width, rupture area, and surface displacement. Bull Seism Soc Am 84:974-1002

Wessel P, Smith W (1991) Free software helps map and display data. EOS Trans AGU 72:441-461

WGCEP (Working Group on California Earthquake Probabilities) (1995) Seismic hazards in southern California: probable earthquakes, 1994 to 2024. Bull Seism Soc Am 85:379-439

WGCEP (Working Group on California Earthquake Probabilities) (2003) Earthquake probabilities in the San Francisco Bay Region: 2002-2031. U.S. Geol. Surv. Open-File Report 03-214, 234 pp 